\title{
Investor Sentiment: Too Contagious to Ignore?
}

\author{
Amar Soebhag $^{1}$ \\ ${ }^{1}$ Tinbergen Institute, Rotterdam, the Netherlands \\ Correspondence: Amar Soebhag (Mphil student Econometrics), Tinbergen Institute, Rotterdam, Zuid-Holland, 3062 PA, \\ the Netherlands.
}

Received: November 2, 2017

Accepted: November 20, 2017

Available online: November 22, 2017

doi:10.11114/afa.v4i1.2810

URL: https://doi.org/10.11114/afa.v4i1.2810

\begin{abstract}
This article empirically investigates the role of investor sentiment as a determinant of financial contagion during crises periods. The focus is on developed equity markets as well as emerging equity markets during 1990-2015. By using a multivariate GARCH methodology, cross-equity market correlations are documented to be substantially increasing during financial crises. Investor sentiment is negatively related to cross-equity market correlation. This inverse relationship becomes even stronger during times of financial crises, indicating the existence of financial contagion. This finding can be motivated by loss-averse and ambiguity-averse investors in equity markets. The relationship between investor sentiment and cross-equity market correlation persists after controlling for trade linkages, financial linkages, and other macroeconomic similarities between countries. The findings are robust to changes in crises definition.
\end{abstract}

Keywords: contagion, financial crises, investor sentiment, multivariate GARCH

\section{Introduction}

The true value of financial stability is best exposed in its absence, namely in periods of system-wide failures of financial markets. For example, the recent global financial crisis (GFC) has led to sharp declines in international equity markets. The U.S. equity market lost about $40 \%$ of its market capitalization during this crisis. One remarkable observation was how rapidly this country-specific shock sequentially transmitted from one market to another, around the globe. Not only did asset prices plunge around the globe, but the crisis also jeopardised real economic growth.

The financial turmoil of 2007-2009 has increased the need for financial stability among investors, and policy makers alike. Simultaneously, cross-financial market linkages strengthened over time due to global financial integration. This development makes the global financial system more prone to spill-over and contagion effects, thereby increasing the likelihood of a financial crisis. In addition, financial markets tend to exhibit increased return co-movement during episodes of high market volatility (Longin \& Solnik, 2001). This suggests the existence of time-varying correlations between financial markets.

This suggestion poses a serious challenge for the asset management industry, regulators, and academics since the underlying nature of the correlation provides practical value for them. For asset managers, diversification benefits that can be achieved for asset portfolios are impacted by the correlation between assets. The lower the correlation between assets, the higher the diversification benefit and the lower the portfolio risk. In the presence of time-varying correlation, these diversification benefits may unsolicited fluctuate with the state of the market, leaving large asset portfolios exposed to cross-border - and cross-asset shocks. From the perspective of a regulator, it might be possible that a destabilising country-specific shock spills over through another country, thereby negatively affecting the financial stability. In addition, policy responses to crisis heavily depend on the nature of the transmission channel across financial markets.

A challenge for academia lies in the estimation and conceptualisation of such (dynamic) asset market linkages and correlations between asset markets. Previous, both theoretically and empirically, researchers have taken the challenge to model as well as to identify contagion effects between asset markets. The theory on contagion effects, firstly, shows no universally acceptable definition of contagion. In general, contagion is defined as a significant increase in cross-market linkages after a shock (Longin \& Solnik, 1995). It conveys the idea that transmission mechanism is discontinuous due to financial panics. In addition, the theoretical work on financial crises considers an extensive amount of reasons for crises to contagiously appear in clusters and identifies several transmission channels (Masson, 1999). Some models are 
based on behavioural aspects of individuals and assume that the investor behaviour changes after a large negative shock. On the other hand, it can be argued that such shocks are propagated via "economic fundamentals".

Although there exists a certain degree of ambiguity on what contagion exactly contains, empirical work has been focused on measuring contagion effects using various econometric procedures. Especially this area shows sharp disagreement on the existence of contagion effects during crises periods. In a seminal study, King \& Wadhwani (1990) measured contagion as a significant increase in the correlation coefficient between stock returns. Their findings suggest that the degree of correlation had increased after October 1987, after analysing US, UK, and Japanese equities. Lee \& Kim (1993) extend this analysis to other major markets and provides similar results. Forbes \& Rigobon (2002) argue that simple correlation analysis provide biased results (in presence of heteroscedasticity), in the context of financial contagion. Using an adjusted correlation coefficient, Forbes \& Rigobon (2002) find that increases in correlation are due to increased interdependence, and not due to contagion. In a different fashion, Dungey \& Martin (2001) estimate a factor model of correlation analysis, while Hartmann, Straetmans \& De Vries (2004) use an extreme dependence measure.

This study also accepts the challenge to investigate contagion effects between asset markets over time in order to provide a deeper understanding of the dynamics between equity markets. The purpose of this article is multiple. First, this paper models time-varying correlations by using a multivariate GARCH model to assess whether equity markets show increased return co-movement during 1990-2015. Second, the aim is to assess the explanatory power of investor sentiment in explaining financial contagion, while controlling for macroeconomic fundamentals. Earlier literature has been focused on examining the fundamental determinants of contagion (such as trade). For example, Syllignakis \& Kouretas (2011) find that macroeconomic fundamentals and monetary variables have substantial explanatory power in explaining time-varying correlations between financial markets. Fluctuations in investor sentiment are often mentioned as an element that could explain financial crises (White, 1990; De Long \& Shleifer, 1991). Baker \& Wurgler (2006) document that investor sentiment systematically affects the cross-section of asset returns. Especially assets that are hard to arbitrage are prone to investor sentiment. Baker, Wurgler \& Yuan (2012) document that investor sentiment in one market may affect investor sentiment through private capital flows. In addition, the authors find that high current sentiment predicts low future returns. Following this line of reasoning, one might argue that during financial crises, when current investor sentiment is low, asset prices are decreasing. Since investor sentiment is contagious, asset prices may decrease in other markets as well. This line of reasoning is consistent with financial contagion and hints the potential role of investor sentiment in explaining financial contagion. Yet, the role of investor sentiment with respect to contagion remains unexplored. Third, this article touches upon the question whether contagion effects are stronger in emerging markets than developed markets. Only Celik (2012) specifically analysed this and finds that emerging equity markets are more sensitive to contagion effects than developed markets.

The main results reveal that cross-equity market correlations increase substantially during financial crises. Such increases can potentially be motivated by changes in fundamentals (interdependence) and by changes in investor behaviour (contagion). This article documents that the latter motivation explains increases in cross-equity market correlations during periods of financial crises. This finding persists after the inclusion of a broad set of control variables, allowing for endogenously determined crises periods, and the use of left tail dependence instead of correlations. These results are weaker for the sovereign bond market, where it is documented that the role of investor sentiment in explaining sovereign bond correlations is limited. However, changes in correlations between equity markets (and also for the sovereign bond market) is not solely driven by financial contagion. Common random shocks and interdependence do also exhibit explanatory power. It is documented that the Fed fund rate, the U.S. Terms of Trade, and exchange volatilities are negatively related to the dynamic conditional correlations. Lastly, there is not sufficient evidence in favour of stronger contagion effects in emerging markets. Only during the GFC, it is found that contagion effects between the U.S. and emerging equity markets are significantly stronger than contagion effects between the U.S. and developed equity markets.

The outline of the paper is structured as follows. In section 2the related literature is presented, in conjunction with the hypotheses of interest. Section 3 elaborates on the data analysed during this research project. Section 4 elaborates on the research methodology that has been deployed. Section 5 presents the results and the corresponding economic interpretation. Section 6 is centred on robustness checks. Section 7 offers conclusive and reflective remarks.

\section{Literature Overview}

This section shortly addresses the theoretical causes and transmission of contagion. The set of theoretical work can be, broadly speaking, divided into a set of "fundamental" theories and a set of "behavioural" theories. These two sets of theories are not necessarily mutually exclusive. The first set of theories assume that transmission mechanisms are the same during a crisis as during more stable periods. Thus, cross-market linkages do not change after a shock according to these theories. In that case, financial crises resulting from interdependency should be predictable using macroeconomic 
fundamentals. On the other hand, behavioural theories aim to explain why transmission channels change during volatile periods and thus why contagion occurs. Any test of contagion should be supportive of the latter set of theories. Afterwards, an empirical literature review will be provided with respect to the quantification of contagion effects in financial markets. This article draws clear-cut testable predictions from both the theoretical as well as the empirical literature.

\subsection{Theoretical Overview}

\subsubsection{Fundamental Causes}

Fundamental theories stress out that spill-over effects result from the interdependence among economies. Thus, transmission channels after a shock do not differ significantly than before shock. Cross-market correlations are rather a persistency of linkages that existed even before the shocks. Shocks will be transmitted across economies due to real and financial linkages between these economies.

The most obvious form of interdependence between markets is caused by trade linkages. First, given high levels of bilateral trade between two trade partners, an adverse shock in one country is likely to affect its trading partners, via the loss of competitiveness and through the fall in demand in the country where the adverse shock was initiated (Gerlach \& Smets, 1995). The trading partner may experience crashes in asset prices, significant capital outflows or become the target of a speculative attack because investors predict a deterioration in the trade accounts of an economy. Another trade linkage is third-market competition, whereby a financial crisis in one country is contagious to other countries that export to the same third market. Lastly, interdependence may occur due to competitive devaluation. In this scenario, an economy loses competitiveness when the currency of a major trading partner is devalued. Such devaluations may especially put pressure on economies that have pegged currencies. Regulators and policy-makers may attempt to restore the competitiveness of an economy by also devaluing its currency, in response to the initial devaluation. If investors predict that such strategic interactions are probable, they are likely to withdraw capital from these countries. Thereby bringing a fall in asset prices and further declination in the currency value. Eventually, this may trigger a crisis.

Fundamental causes also include shocks that are transmitted through financial linkages. Financial linkages stem from the process of increasing globalisation as countries try to be more economically integrated with global financial markets, thereby causing a higher level of interdependencies. The first linkage is the "common lender" effect, which was proposed by Kaminsky \& Reinhart (2000). It asserts that a country that shares a common lender as a country struck by a crisis is more likely also to experience a crisis. The crisis in the latter country creates a need to reassess and rebalance the overall risk exposure of the creditor's asset portfolio. The former country might face withdrawal and retrenchment from these common creditors induced by a crisis in the latter country. The second financial linkage is the cross-border capital flow between two countries. Similar to multilateral trade, more capital flows between economies lead directly to more interdependence.

Lastly, common random shocks is often mentioned as a fundamental cause. A common random shock is a change in the global economic environment, which adversely impacts the fundamentals of several countries simultaneously. For example, variation in the U.S. interest rate adversely affected the funding of emerging market economies, potentially resulting in a crisis in some of these economies (Moser, 2003). In addition, the strengthening of the U.S. dollar against the yen in 1995-1996 has been shown to play a significant role in the weakening of East-Asian economies and its crisis in 1997-1998 (Corsetti et al. 1999). Such commonalities lead to co-movement of asset prices or capital flows in those affected economies such that cross-country correlations could increase. Therefore, proxies for common random shocks (such as oil prices) may to explain variation in the correlation between two equity indices. Such evidence would favour interdependence rather than contagion.

\subsubsection{Behavioural Causes}

Behavioural theories pertain the transmission of financial crises which is not attributable to observed disruptions in macroeconomic or other fundamental variables. These theories argue that such transmission is solely due to investor behaviour of financial agents. This type of contagion is often said to be the result of irrational behaviour, such as financial panic, herding behaviour, and investor sentiment. Several theories explain investor-based contagion from different angles and can be classified into three groups: multiple equilibria, liquidity problems, and herding behaviour. Below the latter two groups are discussed.

With respect to liquidity shocks, Goldfajn \& Valdes (1997) propose a theoretical model whereby a crisis in a country may reduce the liquidity of market participants. This results in investors recomposing their portfolio of financial assets and sell assets in other markets in order to satisfy margin calls, or to meet regulatory requirements. If the liquidity shock is large enough, a crisis in one country may increase the extent of credit rationing and force investors to sell their holdings in other countries that were not affected by the initial crisis. Brunnermeier \& Pedersen (2008) show that funding liquidity and market liquidity are mutually reinforcing and might induce liquidity spirals during crises periods. 
Traders become reluctant to take on positions when funding liquidity is low, which in turn lowers market liquidity, leading to higher price sensitivity. When investors do not meet their margin calls, they will sell their assets. Since liquidity is low, the prices of these assets drop substantially, thereby decreasing the value of these assets in other portfolios. This results in other investors selling assets to meet their margin requirements, thus creating a negative spiral of fire-sales. Kodres \& Pritsker (2002) explain financial market contagion using a rational expectation model of asset prices. In this model, the long-run value of assets is determined by systematic risks and country-specific factors. According to Kodres \& Pritsker (2002), contagion occurs when informed investors act, due to the arrival of private information on a country-specific factor, by rebalancing the exposure of portfolios to the shared macroeconomic risks in other countries. In the other countries, uninformed investors are not able to identify the source of the change in the asset demand. Thus, these investors rebalance as if the information is related to the own country-specific factor. That being said, an idiosyncratic shock generates excess co-movement across countries' asset markets. The model, empirically, implies that economies with larger liquid markets should be more vulnerable to contagion. Small and illiquid markets are likely to have a lower weight in international portfolios and are thereby shielded from contagion as generated in the model of Kodres \& Pritsker (2002).

Lastly, explanations for financial contagion are based on herding behaviour of investors. Uninformed investors frequently make investment decisions based on the actions of others, causing rational herding behaviour. In a seminal paper, Bikhchandani, Hirshleifer \& Welch (1992) model mass behaviour due to informational cascades. According to the authors, information cascade arises when it is optimal for an agent, after observing another agent ahead of him, to follow the behaviour of the agent ahead of him without any regard to the own information of the individual. These cascades occur under mild conditions and often will go in the wrong direction. In these cases, a few early individuals have a disproportionate impact on others. The decisions of others in itself may reflect private information and that individuals also consider the decisions of other people. Under sequential decision making, there exists a herding externality with a positive feedback loop. If agents join the crowd, there is more incentive for outsiders to join the crowd too. The decisions of the first few decision makers, which are not per se correct, determine where the crowd forms and grows, thereby amplifying the impact of the decision made by the initial individuals.

Devenow \& Welch (1996) argue that herding is an irrational phenomenon. They propose that investors disregard their own information set and follow others due to an intrinsic preference for conformity with the market consensus and certainty. Christie \& Huang (1995) argue that herding behaviour is more pronounced during market stress and extreme market return movements. In times of uncertainty, following the market consensus reduces the concern of making incorrect decisions. This suggests that behavioural herding patterns play a role in explaining financial crisis. Chiang \& Zheng (2010) study herding behaviour in global stock markets. The evidence shows that a financial crisis induces herding behaviour, which in turn produces contagion effects. Thus, herding behaviour drives contagion effects. Another documentation is that herding behaviour is more likely in emerging markets in comparison with developed markets (Economou, Kostakis \& Philippas, 2011; Celik, 2012). The relative lack of transparency, weak reporting requirements, lower accounting standards, lax enforcements of regulations, and costly information acquisition inevitably lead to herding behaviour in emerging markets. This raises the following hypothesis:

\section{Contagion effects are stronger in emerging markets}

Hwang \& Salmon (2009) propose a model which incorporates the interaction between sentiment and herding to show that herding activity increases with (global) sentiment. According to the authors, individual asset returns decrease when market-wide sentiment is lower, regardless of systematic risk. There exist several channels through which financial contagion due to investor sentiment occurs. One, pessimistic international investors may sell-off securities from different markets simultaneously, thereby rapidly declining prices across markets. Second, sentiment in a foreign market affects sentiment in the domestic market directly due to herding behaviour of noise traders, through which market prices are affected. It is documented that "word-of-mouth" social interactions can affect sentiment and investment decisions (Brown, Ivkovic, Smith \& Weisbenner, 2008). Therefore, it is likely that proxies for investor sentiment might drive contagion. Baker, Wurgler \& Yuan (2012) investigate whether sentiment is contagious across countries. The absolute value of U.S. capital flows with other countries is used to obtain cross-sectional variation in the extent of integration between these markets. They do not only find that local and global sentiment predict the cross-section of those countries' returns, but also that capital flows appear to be one mechanism by which sentiment spreads across markets and affects global sentiment. These findings imply that any quantifications of return comovement between equity markets should (partially) be driven by proxies for investors. Therefore, the following hypothesis will be tested as well.

\section{Contagion is driven by proxies for investor sentiment during crises periods.}

However, it is challenging to distinguish both conceptually and empirically whether contagion occurs due to innovations in the fundamentals of a country or to changes in investor behaviour. 


\subsection{Econometric Overview}

Testing for contagion implies a number of econometric challenges, especially with respect to the identification and empirical conceptualisation of contagion. The simplest methodology is static correlation analysis.A significant increase in the correlation in returns between two markets after a shock can be interpreted as an increase in the transmission mechanism between the two markets, indicating the occurrence of contagion. In a seminal study, King \& Wadhwani (1990) measured contagion as a significant increase in the correlation coefficient between stock returns. These authors find that the degree of correlation had increased after October 1987, after analysing US, UK, and Japanese equities. Lee \& Kim (1993) find evidence of the existence of contagion in twelve major stocks markets after the 1987 U.S. stock market crash. On average, the correlation increased from 0.23 , before the crash, to 0.39 after the crash. Calvo et. $\mathrm{Al}$ (1996) document a significant increase in the correlation between stock prices and in Asian and Latin-American countries. Correlations during calm periods were significantly lower than the correlations in crisis periods in debt markets, and currencies markets. All these researchers provide evidence that shocks originating from one market can be transmitted to other markets, resulting in a source of substantial financial instability and turmoil. Therefore, the last hypothesis of this paper is as follows:

\section{Cross-market correlations between equity markets increase substantially during crisis periods.}

To test this hypothesis, correlation analysis will be used as an intuitive starting point. However, this article will rely on more advance methodologies as simple correlation analysis has severe limitations. First, static correlations are biased upwards in presence of heteroscedasticity (Forbes \& Rigobon, 2002). Second, correlation tests may not be reliable when it comes to assessing the stability of a dependence structure (Rodriguez, 2007). Third, static correlations do not take volatility continuously into account, while time-varying volatility can be perceived as a stylized fact of stock returns (Tse \& Tsui, 2002). Fourth, the use of correlations as dependence measures is only justified for multivariate normal distributions. It is generally accepted that financial time series do not meet the criteria of multivariate normality, causing correlations to fail to reveal the underlying dependence structure.

By now, it is well accepted that correlation analysis needs further refinements in order to estimate contagion effects. One strand of literature focuses on stochastic modelling of time-varying volatility processes in financial time series using GARCH class specifications. Such specifications allow capturing the dynamic nature of the contemporaneous correlation coefficient. Several parsimonious multivariate GARCH specifications have been used in the literature. Longin \& Solnik (1995) were among one of the first to apply a multivariate GARCH model in the context of modelling cross-market linkages. Using monthly excess returns for seven major economies over the period 1960-1990, the authors show that the international correlation matrices are time-varying and that the correlations have been increasing in times of crises. Engle \& Sheppard (2001) developed the DCC-GARCH (Dynamic conditional correlation - GARCH) to examine time-varying correlations. DCC-GARCH is able to directly adjust the correlation for time-varying volatility continuously. Chiang, Jeon \& Li (2007) and Celik (2012) both utilise the DCC-GARCH to estimate time-varrying correlations between financial markets. Both studies find support for contagion as measured by increase correlations during financial crises. In this article, the DCC-GARCH will also be adopted.

\section{Data}

\subsection{Stock Market Returns}

In order to provide a measure of comovement over time, first the stock market returns needs to be defined. The sample consists of monthly dollar denominated stock market index returns retrieved from Thomson Reuters Datastream. Monthly returns are defined as $r_{t}=\ln \left(p_{t}\right)-\ln \left(p_{t-1}\right)$. There are 11 countries in the sample, consisting of seven developed countries and four other emerging markets (as classified by Dow Jones): The United States of America (US, S\&P 500), Germany (DE, DAX), France (FR, CAC 40), United Kingdom (UK, FTSE 100), Japan (JP, Nikkei 225), Netherlands (NL, AEX) and Canada (CN, TSX). The emerging markets consist of China (SSE composite), Russia (MICEX), India (NSE), and Mexico (MEXBOL). The sample spans the period from January 1, 1990, till September 30, 2015. It covers known episodes of global crisis and contagion periods, such as the Asian Flu (1997), the Russian crisis (1998), the Dot-com bubble (2001), the GFC (2007), and the European debt crisis (2009). Due to limited data availability, the sample for China and Russia starts in 1/1/1991 and 22/9/1997 respectively.

Table 1 presents the descriptive statistics of the examined stock market index returns. There is some variation in the average monthly return, with Japan exhibiting the lowest return (-19.9\%) and China the highest $(101.5 \%)$. A notable observation is the dispersion in the standard deviation between emerging markets and developed countries. The former group has a larger standard deviation. This possible could imply that emerging markets are more prone to contagion. All countries face negative skewness, implying fat left tails. The null hypothesis of normality is rejected in all cases, using the Shapiro Wilk test. Most countries do not exhibit significant autocorrelations, as indicated by the Ljung-Box test statistic. The null hypothesis of no ARCH effects is rejected for all countries, except China. Table 1 also provides some 
preliminary support for the hypothesis that the correlation between two equity markets increases during crises periods. During periods of crises, the correlation (between the U.S. stock market and other markets) increases. It seems to be that the change in correlations is larger for emerging markets, compared to developed markets. Lastly, note that the level of the correlation for emerging markets is substantially lower than for developed countries, on average.

Table 1. Descriptive statistics

\begin{tabular}{|c|c|c|c|c|c|c|c|c|c|c|}
\hline Index (Country) & From & Min & Max & Mean & SD & SW & $\mathrm{LB}(10)$ & $\mathrm{ARCH}(5)$ & $\rho_{n c}$ & $\rho_{c}$ \\
\hline S\&P 500 (U.S.) & $1 / 1 / 1990$ & -0.186 & 0.106 & 0.005 & 0.042 & $0.967^{* * *}$ & 7.255 & $33.214^{* * *}$ & - & \\
\hline DAX 30 (Germany) & $1 / 1 / 1990$ & -0.286 & 0.216 & 0.005 & 0.067 & $0.956^{* * *}$ & 7.541 & $17.164^{* * * *}$ & 0.710 & 0.839 \\
\hline CAC 40 (France) & $1 / 1 / 1990$ & -0.247 & 0.143 & 0.003 & 0.061 & $0.979^{* * * *}$ & 12.021 & $27.254^{* * * *}$ & 0.708 & 0.834 \\
\hline FTSE 100 (U.K.) & $1 / 1 / 1990$ & -0.211 & 0.131 & 0.003 & 0.048 & $0.985^{* * *}$ & 6.250 & $32.816^{* * * *}$ & 0.734 & 0.846 \\
\hline AEX 25 (Netherlands) & $1 / 1 / 1990$ & -0.316 & 0.151 & 0.004 & 0.061 & $0.938^{* * *}$ & 5.619 & $36.431^{* * *}$ & 0.718 & 0.846 \\
\hline NIKKEI 225 (Japan) & $1 / 1 / 1990$ & -0.199 & 0.245 & -0.002 & 0.065 & $0.989^{* * *}$ & 13.293 & $36.665^{* * * *}$ & 0.412 & 0.663 \\
\hline TSX (Canada) & $1 / 1 / 1990$ & -0.320 & 0.187 & 0.003 & 0.057 & $0.944^{* * *}$ & 9.812 & $11.124^{* * * *}$ & 0.741 & 0.843 \\
\hline SSE Comp. (China) & $1 / 1 / 1991$ & -0.485 & 1.015 & 0.010 & 0.131 & $0.813^{* * *}$ & $16.135^{*}$ & 7.003 & 0.065 & 0.397 \\
\hline MICEX (Russia) & 22/9/1997 & -1.043 & 0.348 & 0.001 & 0.120 & $0.824^{* * *}$ & $34.416^{* * *}$ & $31.889^{* * *}$ & 0.402 & 0.672 \\
\hline NSE (India) & 1/1/1991 & -0.369 & 0.356 & 0.005 & 0.093 & $0.976^{* * *}$ & 8.947 & $17.479^{* * *}$ & 0.223 & 0.725 \\
\hline MEXBOL (Mexico) & $1 / 1 / 1990$ & -0.461 & 0.198 & 0.009 & 0.092 & $0.926^{* * *}$ & $18.802^{* * * *}$ & $23.888^{* * * *}$ & 0.536 & 0.818 \\
\hline
\end{tabular}

The table presents the summary statistics for the stock market indices in the dataset, using monthly return series. "From" is the start date of the return series of a particular index. "SD" denotes the standard deviation. "SW" denotes the Shapiro-Wilk test statistic for non-normality. "LB" denotes the Ljung-Box statistic for autocorrelation with 10 lags. "ARCH" is Engle's test for Arch effects. $\rho_{n c}$ denotes the correlation during non-crises periods between the S\&P500 and the equity market from the $\mathrm{j}$ 'th row. Likewise, $\rho_{c}$ shows the correlation during crises periods. $* * *, * *$, and $*$ denote statistical significance at the $1 \%, 5 \%$ and $10 \%$ levels, respectively. The data ends 30/9/2015.

\subsection{Investor Sentiment}

To test whether contagion in stock indices returns is driven by investor sentiment, several proxies are utilized as investor sentiment is not directly observable. First of all, Baker \& Wurgler's investor sentiment index (2006) is used to identify investor sentiment on a monthly frequency. Data is retrieved from the website of Jeffrey Wurgler. This composite index equals the first principal component extracted from six indirect measures of U.S. focused investor sentiment: trading volume (NYSE turnover), dividend premium, closed-end fund discount, the P/E ratio, the equity share in new issues, the number of IPOs, and their first-day returns. Specifically, the orthogonalized sentiment index is deployed which is free from business cycle related variations. Therefore, this sentiment index is expected to be uncorrelated with macroeconomic fundamentals. Positive values of this index are associated with a high level of investor sentiment.

However, Baker \& Wurgler's index is an indirect measure of investor sentiment. The investor sentiment indicator from the American Association of Individual Investors (AAII) offers a more direct measure to capture investor sentiment. This metric is directly obtained from the investors that participate in the weekly AAII's survey on their expectations pertaining the stock market performance in the next six months. The sentiment survey provides three variables, $B U L L_{t}, B E A R_{t}$, and NEUTRAL $L_{t}$, which measures the proportion of individual investors who are bullish, bearish, and neutral on the U.S. stock market, respectively. $N E U T R A L_{t}$ is excluded in the regression analysis to avoid perfect multicollinearity.

Lastly, the CBOE's Volatility Index of the S\&P 500 (VIX) is used as a proxy of investor sentiment. The VIX index is a measure of implied volatility, which is the expectation of the volatility for the S\&P500 over the next 30 days. The VIX index is perceived as a leading barometer of investor sentiment in global capital markets, and is often referred as the "fear index". This index is obtained from Datastream.

\subsection{Control Variables}

Several control variables are used in order to distinguish contagion from interdependence. Oil and gold price returns are used as proxies for common random shocks since any change in these prices affects all countries simultaneously (Edison, 2003). In addition, the overnight discount rate of the FED is used as a proxy for the international interest rate. The international interest rate is a determinant of international capital flows. Countries that depend on these flows are sensitive to changes in the international interest rate, which may give rise to triggering a financial crisis (Frankel \& Rose, 1996).

Monthly import and export flows (in USD) between the U.S. and all other countries are obtained from the Direction of Trade Statistics of the IMF to account for trade linkages. Rather than using the current account, separating export flows and import flows allows to reveal a more detailed description of the source of time-varying cross-equity market correlations. For each country, the monthly change in import from / export to the U.S. is calculated by using a $\log$-transformation. To directly take the relative competitive advantage due to relative price changes into account, the Terms of Trade (ToT) of the U.S. relative to all other countries will be used. A loss in competitiveness may deteriorate 
the current account and thereby hurt the real sector. Lastly, to take competitive devaluation into account, (conditional) exchange rate volatilities are obtained via a $\operatorname{GARCH}(1,1)$ model. Unstable exchange rates are partially due to strategic and competitive devaluations between countries. Lower exchange rate volatility is therefore expected to be associated with higher co-movement between markets. In addition, from a financial perspective, investors price currency risk, which is determined by (expected) exchange rate volatility. Exchange rate changes alter the return a foreign investor's yields in terms of domestic currency. However, if currency volatility is lower, the costs of rebalancing portfolios is lower. This implies a higher co-movement of equity markets as well. Monthly exchanges rates relative to the USD are obtained from Datastream for the countries in the sample. For European countries, the exchange rates are corrected for the introduction of the Euro.

To control for macroeconomic similarities, monthly inflation rates (via the CPI) and industrial production growth data for each country is obtained. The inflation rate is likely to be correlated with high nominal interest and may proxy macroeconomic mismanagement, which negatively affects the real sector and the banking system (Semlali, Collyns, 2002). Negative growth in the industrial production may induce a crisis in the real sector which precedes financial crises (Edison, 2002).

For each country, the monthly aggregate sales (purchase) flows of bonds and stocks, to (from) that corresponding country, to U.S. citizens is identified. These monthly aggregates (expressed in billion dollars) are obtained from the U.S. Department of the Treasury. The reason to utilise these variables is that they are indicators of cross-border capital flows and foreign participation in the U.S. financial market. These variables thereby contribute to financial linkages (through cross-border capital flows) and financial integration (through domestic participation) simultaneously. High values of these flows are associated with a higher level of interdependence between financial markets, due to increased financial integration. The M2 supply growth is used as a simple proxy for funding liquidity, which is the ease at which funding is obtained. High levels of growth in M2 may lead to excess funding liquidity, thereby amplifying the growth of asset bubbles. Monthly M2 data is obtained from all corresponding domestic central bank from the countries in the sample. For European countries, the time series are adjusted for their contribution to the ECB's M2 supply after the EMU. Lastly, the liquidity factor of Pastor \& Stambaugh (2003) is used as a proxy of U.S. market liquidity, which is the ease at which assets are traded. This factor is based on order flows and expected return reversals. According to Brunnermeier \& Pedersen (2008) funding - and market liquidity are important drivers of bubbles and crashes.

\section{Methodology}

\subsection{Modelling Co-Movement between Equity Markets}

The DCC GARCH model is used to estimate time-varying correlation between markets. In such models, the conditional variances and covariances of the residuals follow an ARMA-structure. A nonlinear combination of univariate GARCH models with time-varying cross-equation weights is used to compute the conditional covariance matrix of the residuals. Thus, by employing the DCC GARCH model, one is able to capture the information of time-varying characteristics of the correlation matrix. In addition, the DCC GARCH model offers several benefits. Firstly, the DCC GARCH estimates correlation coefficients of the standardised residuals, thereby accounting for heteroscedasticity directly. Moreover, the model offers flexibility in the mean equation to specify the model correctly. Lastly, and most importantly, it allows to examining multiple asset returns simultaneously in a parsimonious manner. In a single representation, multiple pair-wise correlations coefficient series can be obtained through this methodology. Let the multivariate return equation be specified in each separate equation, as:

$$
R_{t}=X_{t} \beta+\varepsilon_{t}, \quad \varepsilon_{t} \mid \Omega_{t} \sim N\left(0, H_{t}\right)
$$

Where $R_{t}$ represents a $n \times 1$ vector with the $i$ 'th element denoting the $i$ 'th dependent variable corresponding to the $i$ 'th equation. $\beta$ represents a $k \times 1$ vector of parameters, and $X_{t}$ denotes a $n \times k$ data-matrix. The multivariate conditional variance is modelled as $H_{t}=D_{t} R_{t} D_{t}$. Estimating $H_{t}$ involves a two-step estimation procedure. $D_{t}$ is a $n \times n$ diagonal matrix containing time-varying standard deviations $\left(\sqrt{h_{i i, t}}\right)$ on its diagonals. Each time-varying standard deviation comes from a univariate GARCH model in the first step of the estimation procedure. In the second step, each equity index return residual $\epsilon_{i, t}$ is rescaled by its time-varying standard deviation from step one, which provides a parameters $\gamma_{i, t} . \gamma_{i, t}$ in turn is used to estimate the conditional time-varying covariance matrix of $\gamma_{t}$. The evolution of this time-varying covariance matrix is given by:

$$
\Sigma_{t}=\left(1-\lambda_{1}-\lambda_{2}\right) \Sigma^{*}+\lambda_{1} \gamma_{t-1} \gamma_{t-1}^{T}+\lambda_{2} \Sigma_{t-1}, \quad \lambda_{1}+\lambda_{2}<1
$$

$\Sigma_{t}$ is a $n \times n$ time-varying covariance matrix of $\gamma_{t}$, and $\Sigma^{*}$ is the expected value of the outer product of $\gamma_{t}$. $\Sigma_{t}$ can be rescaled into a time-varying correlation matrix $P_{\mathrm{t}}$ by simply observing that $P_{t}=\operatorname{diag}\left(\Sigma_{t}\right)^{-\frac{1}{2}} \Sigma_{t} \operatorname{diag}\left(\Sigma_{t}\right)^{-\frac{1}{2}}$. The aim is to estimate this matrix $P_{t}$. In this paper, for each country, the time-varying correlation between the corresponding equity market and the U.S. equity market is estimated. In the mean equation, a constant-only model will be specified for simplicity. In the variance equation, a $\operatorname{GARCH}(2,2)$ structure is specified. Student's T-distribution will be used in the 
$\log$-likelihood function, thereby taking the fat tails into account.

\subsection{Seemingly Unrelated Regression}

To analyse the determinants and the dynamics of the estimated dynamic conditional correlations, the following general system of equations is estimated through the use of seemingly unrelated regression (SUR) since dynamic conditional correlations are likely to be contemporaneously correlated.

$$
\rho_{i j, t}=\alpha_{i j}+\psi_{1, i j} S E N T_{t}+\psi_{2, i j} B E A R_{t}+\psi_{3, i j} B U L L_{t}+X_{i j, t}^{T} \gamma_{i j}+\sum \delta_{i j, t} d_{t}+\epsilon_{i j, t}
$$

Where $\rho_{i j, t}$ is the dynamic conditional correlation between country $i$ and the U.S. at time $t$. SENT $T_{t}$ denotes Baker and Wurgler's sentiment indicator. $B E A R_{t}$ and $B U L_{t}$ are AAII's bearish and bullish sentiment indicator. The neutral indicator is excluded to overcome perfect multicollinearity. $X_{i j, t}^{T}$ is a matrix consisting of the control variables. $\sum \delta_{i j, t} d_{t}$ is a set of time dummies, also including the NBER recession time dummy. In SUR, the larger the contemporaneous correlation between the errors $\left(\epsilon_{i j, t}\right)$, the larger is the information gain of FGLS compared to OLS (Moon \& Perron, 2006). This will result in SUR being more efficient than OLS. Contemporaneous correlation is assessed by the Breusch-Pagan LM test.

To test hypothesis 3, the SUR regression is estimated only with time dummies. First, the NBER time dummy is simply used. Afterwards, separate time dummies are employed for each different crisis in the sample, including the Mexican peso crisis (1994), the Asian currency crisis (1997), the Russian rubble crisis (1998), the Dot-com Bubble (2000), the GFC (2007) and the European debt crisis (2010). This will not only allow to assess whether cross market correlations increase substantially during crisis periods, but also provide insight whether this change differs by crisis. Furthermore, these separate time dummies are merged to one new time dummy $\left(D_{C R I S I S, t}\right)$ which denotes whether a crisis occurred in month $t$. This dummy will be used in the further analysis unless specified otherwise. To test hypothesis 2 , the full SUR equation is estimated with all variables of interests and control variables. To test hypothesis 1 , the coefficients of the sentiment indicators will be tested for joint equality during crisis periods. If these effects do differ across developed and emerging markets, there is evidence in favour of hypothesis 1.

\section{Results}

Figure 1 shows the predicted in-sample dynamic conditional correlation between the U.S. and all other developed markets (left), and between the U.S. and all emerging markets (right). There are three striking patterns, in both figures, that can be observed. First, the correlation between the U.S. and other countries increases during known episodes of high financial stress. An increase in the correlations can be observed for each pair in the period between 2000-2003 and 2008-2009. These episodes correspond to the Dot-Com bubble and the GFC. Between the U.S. and European countries, an increase can be observed around 2013, consistent with the European sovereign debt crisis. Second, there seems to be an upward trend in the time-varying correlations over time. This observation is consistent with the financial integration of markets over time. Lastly, there exists heterogeneity in these correlations across the pairs. European countries, Canada, and Mexico, have a higher level of correlation with U.S. in general. Again, this finding is consistent with the high interdependence between these countries and the U.S. For the emerging markets, the level of correlations seem to be lower. These figures suggest that the DCC-GARCH estimates are able to capture dynamic correlations that are consistent with historical events and patterns.

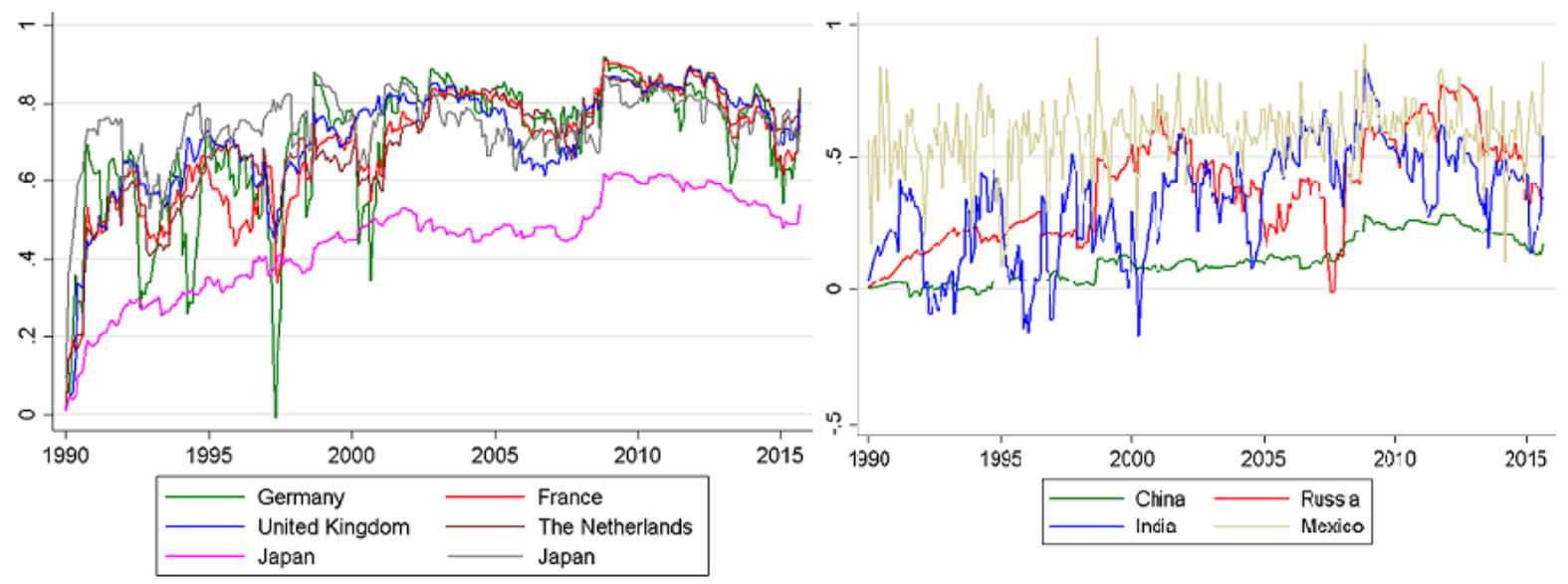

Figure 1. Time-varying correlation estimates

Table 2 (see appendix) provides the SUR estimates of three different dummy-variable regressions for each correlation pair with the US. In model 1, the dynamic correlations are regressed on a constant and the NBER time 
dummy $\left(D_{N B E R, t}\right)$. Model (2) uses six different time dummies corresponding to the dates of six financial crisis. Model (3) uses one single time dummy that equals one if one of the six crisis occurred in month $t$. The results from model (1) suggest weak evidence in favour of hypothesis 3 because $D_{N B E R, t}$ is positive across all countries, however not always significant across the countries. The Germany equity market, for example, becomes significantly more correlated with the U.S. equity market. The correlation increases, approximately, by 6.4 percent point during NBER recessions. Yet, for the Netherlands, the correlation increases by an insignificant 2.1 percent point. It might be possible that the NBER recession dates imperfectly proxies the dates of financial crises or that the correlation between specific markets only increases for specific financial crises. To take the latter notion into account, Model (2) provides the estimates of the effect of six different crisis dummies on the dynamic conditional correlation. Indeed, the effects of crisis periods on correlations differ by crisis and by country. Cross-equity market correlations are mostly insignificant and negative for the Mexican 'Tequila' crisis and the Asian currency crisis. The correlation between U.S. equity markets and the Mexican equity market is significantly lower at the $1 \%$ level during the Mexican crisis. This finding, however, is not consistent with hypothesis 3 , as a positive effect of the crisis period was expected. Possibly this has to do with the nature of the crisis, which occurred in the Mexican FX market and subsequently in the Mexican real sector. During this period the Mexican trade - and financial linkages were predominantly disrupted by the increasing volatility of the Mexican Peso rather than irrational causes. A similar explanation also holds for the Asian currency crisis in 1997. All other crises exhibit a consistent positive pattern with respect to the cross-equity market correlations. Especially the GFC and the European debt crisis seems to have the most consistent pattern: each dynamic conditional correlation increases significantly at the $1 \%$ level during these periods. Model (3) uses the aggregated time dummy. For this model, the effect of crisis periods on dynamic correlations is estimated to be positive and significant at the 5\% for each pair. Table 3 provides reasonable evidence in favour of hypothesis 3: cross-equity market correlations seem to increase during periods of high volatility. However, the estimated effect differs by crisis and country.

In order to test whether the increase in correlations is attributable to investor sentiment, these correlations are regressed against four proxies of investor sentiment. In addition, interaction terms between the crisis dummy and these proxies are included. In this setting, contagion occurs when the effect of investor sentiment is significantly stronger during crisis periods. Table 3 contains the results for the three estimated equations. Equation (4) regresses the dynamic correlation on the NBER time dummy, investor sentiment proxies, and the interaction of sentiment with the time dummy. The results show that Baker \& Wurgler's sentiment index has a negative effect on the dynamic correlations (for most cases) at the $1 \%$ significance level. This implies that high investor sentiment on the U.S. stock market is associated with lower correlation during non-crises periods, on average. In addition, this effect seems to be economically sizable. For instance, an increase of one point in the index is associated with a 12.8 percent point decrease in the dynamic correlation between Germany and the U.S.. For the bullish sentiment indicator, a similar finding is obtained. An increase in the proportion of investors that indicate to be bullish on the U.S. stock market is associated with a decrease in the dynamic correlation during non-crisis periods, on average. A one percentage point increase in the bullish indicator is associated with a 0.6 percentage point decrease in the US-German dynamic correlation. Consistent with this line of reasoning, the bearish indicator has a significantly positive effect on the dynamic correlations in seven out of the ten cases. All three investor sentiment indicators seem to have a systematic effect on the dynamic correlations over time. What is more striking, is that this relationship seems to become stronger during periods of crisis. During crisis periods, the effect of $S E N T_{t}$ becomes significantly more negative as indicated by the coefficients of the corresponding interaction term. In ten out of the eleven correlations, this effect is statistically significant at the 5\% level. The hypothesis that these coefficients are jointly zero is rejected at the 5\% level $(F=5.42)$. Therefore, during crisis periods, when investor sentiment is low on average, the dynamic correlations will increase substantially. This finding suggests that the increase in cross-equity market correlations is driven by investor sentiment. This evidence suggests the existence of financial contagion, since it represents changes in financial conditions that are likely to be driven by changes in the behaviour of investors or preferences unrelated to fundamentals. Model (5) replaces the NBER recession dummy with the broader crisis dummy. These results are quantitatively and qualitatively the same, implying that the findings of model (4) also holds when a different crisis specification is considered.

These findings can be motivated by behavioural patterns. When crises unravel with the arrival of a series of negative news, investors with non-bayesian beliefs will negatively overreact to this news (Barberis, Shleifer \& Vishny, 1998). This decline forces loss-averse investors to endure painful losses and deteriorate their sentiment. Thaler \& Johnson (1990) suggest that these losses may have made investors more loss averse, resulting them to rebalance the share of risky assets in their portfolio and thereby causing further price declines. Such portfolios may be internationally diversified, thereby also inducing price declines in foreign assets. Losses can generate contagion between assets when those assets are held by common investors. This will result in portfolio rebalancing of loss averse foreign investors, creating a negative spiral. This negative spiral will result in joint losses in several markets simultaneously, thereby generating a higher co-movement of these markets by definition. Thus, investor overreaction can cause small negative 
shocks to trigger market-wide panics that can spread internationally. A second explanation of the results lies in the "competence hypothesis" (Heath \& Tversky, 1991): an individual's feeling of competency in a given situation is determined by what is known relative to what can be known. During crises periods, market volatility increases. This results in a lower competency of investor to assess the market environment and lowers investor sentiment. According to (Heath \& Tversky, 1991) will increase ambiguity aversion of individuals. In turn, due to this increase in ambiguity aversion, investors are more likely to show herding behaviour. When investors exhibit pessimistic expectations on the market and don't feel sufficiently competent to assess the market environment, the best thing to possibly do is to follow the market consensus. Herding behaviour by ambiguity (and loss) averse investors will increase cross-equity market correlations in crisis periods. These two potential interpretations are not mutually exclusive, but rather reinforce each other simultaneously.

To verify that the effect of investor sentiment on cross-equity markets is not biased, the control variables are included in the SUR regressions. These results of three different models can be found in table 4. For brevity, the bullish and bearish indicator are excluded from the analysis ${ }^{1}$. Model (6) controls for a range of variables that proxy common random shocks that affect all countries in the sample simultaneously, such as gold and oil returns, and the Fed Fund rate $\left(F F R_{t}\right)$. The gold - and oil return estimates are not statistically significant in any case. However, a striking finding is the significant (at the $1 \%$ level) negative effect of the $F F R_{t}$ on dynamic correlations. The FED especially decreases its base rates during a recession as an attempt to promote aggregate demand growth and interbank lending, but also induces higher risk-taking behaviour, not only in the domestic market per se. Furthermore, such decreases may directly cause capital outflows, thereby increasing financial linkages. Model (6) shows that such expansionary policy substantially increases all cross-equity market correlations in the sample. The coefficients of $S E N T_{t}$ in model 6 seem to be higher than those of model (4) and (5). This indicates that the latter estimates are downward biased and that $F F R_{t}$ and $S E N T_{t}$ are positively correlated during non-crises periods. This is consistent with the empirical finding that an interest rate hike can signal a healthy economy, thereby increasing investor sentiment (Kurov, 2010). More important, in 9 out of the 10 correlations, the hypothesis of no sentiment effect during crisis periods is rejected. Thus the evidence of financial contagion persists, even after controlling for common random shocks.

Equation (7) controls for various trade-related and macroeconomic characteristics. The results show that the import and export growth of the U.S. has no statistical significance in explaining the dynamic correlations. Industrial production and inflation rates seem not to exhibit significant explanatory power either. Exchange rate volatility has a significant negative effect on most of the dynamic correlations. This indicates that stable exchange rates result in higher cross-equity market correlations, which is consistent with financial and economic integration. In addition, the U.S. terms of trade (ToT) is negatively associated with dynamic correlations in most countries. A decreasing U.S. ToT implies that price of U.S. exports falls relative to U.S. imports. Therefore, to maintain at least the same level of imports, the U.S. must export more. This will increase trade linkages and economic integration between U.S. and other countries. In addition, consistent with the documented patterns in model (6), the estimated equation (7) in table 5 shows that investor sentiment remains to exhibit a significant adverse effect on the dynamic correlations during crisis periods. A statistically significant negative effect is found at the $1 \%$ level for most correlation time series. Thus, even after controlling for trade linkages and macroeconomic characteristics, the negative effect of investor sentiment on dynamic correlations during crises persists.

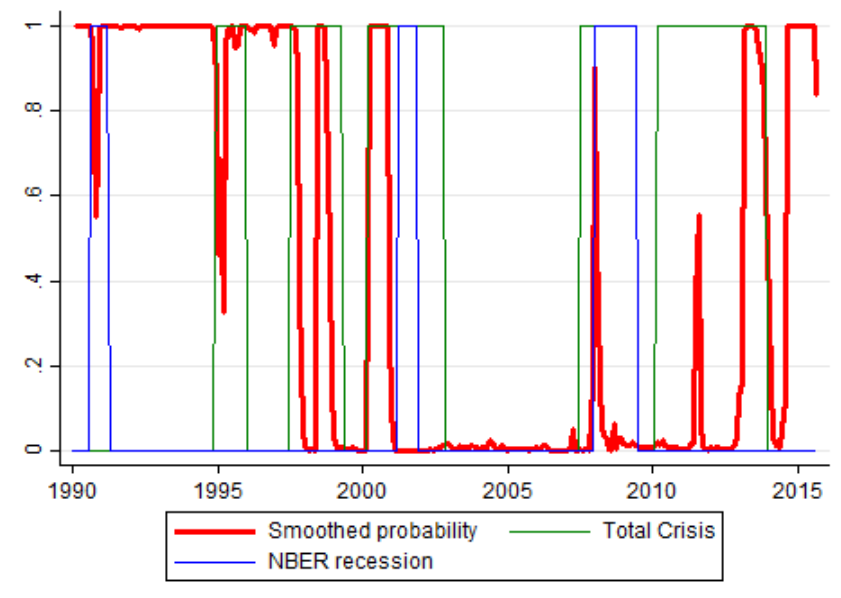

Figure 2. Transition probability and crises dummies for US-Germany

\footnotetext{
${ }^{1}$ Unreported results reveal that the inclusion of these variables provides similar results as was shown in table 3 .
} 
Model (8), table 4, adds several financial control variables, such as Pastor's liquidity factor $\left(L I Q_{t}\right)$, Growth of the M2 money supply $\Delta M 2_{i, t}$, stocks and bonds purchases/sales from/to the U.S. by foreign investors. In addition, an interaction term between $S E N T_{t}$ and $L I Q_{t}$, and an interaction term between this liquidity factor and the crisis dummy is expected. When market liquidity and sentiment is low, it could be expected that pessimistic loss averse investors are not able to sell their assets without fire-sales (Brunnermeier \& Pedersen, 2008). The results, however, show that U.S. the liquidity factor, has no significant effect on the dynamic correlations for any of the countries. Similarly, the growth of M2 money supply of the U.S. and the other countries are not significantly different from zero. Neither a statistically significant effect of the interaction between market liquidity and investor sentiment is documented. The effect of bond and stock flows from and to the U.S. are sporadically significant. In addition, the sign of the effect is not consistent across the countries. The coefficients of the sentiment index remain statistically significant in 9 out of the 10 cases. In addition, this negative effect is significantly stronger during crises periods for all countries except India and Mexico. Thus, the results suggest that controlling for financial linkages does not alter the documented relationship between investor sentiment and cross-equity market correlations.

In sum, it is documented that cross-equity market correlations increase substantially during periods of crises. Thus hypothesis 3 is not rejected. Furthermore, the regressions indicate that the economically sizable and statistically significant negative relation between investor sentiment and dynamic conditional cross-equity market correlation persists after controlling for a large set of control variables. This result shows that financial contagion is driven by investor sentiment. Therefore, hypothesis 2 is not rejected. Despite these results, contagion is not the sole determinant of cross-equity market correlations. Interdependence and common shocks do play a role. Finally, the hypothesis that the coefficients of the interaction between sentiment and the crises dummy are greater in emerging market than developed markets is rejected for all models. Based on these coefficients tests, there is not sufficient evidence to accept hypothesis 1.

\section{Robustness Checks}

The choice of the sample period may give rise to a sample selection bias due to the fact that crisis months are specified ex post, rather than a priori. In this paper, the crisis months are specified ex-post using the time dummies. It must be mentioned that correctly defining the crises periods is to some degree arbitrary, even when official data sources are used. Fong (2003) alleviate this sample selection problem by allowing crisis states to be determined endogenously by using Markov regime switching models. Following these authors, two regimes of contagion risk are identified via a Markov switching model, which takes endogenous structural breaks into account. This allows the data to statistically determine the beginning and the end of each regime/crisis. Model 6-8 will be re-estimated in this Markov regime switching setting.

To illustrate the added value of the Markov switching model, the smoothed transition probability of being in the volatile regime is shown below for US-Germany. Figure (e) reveals that the volatile regime is mostly located within the crises periods based on the exogenously determined time dummies. However, there some small differences. For instance, the length of the crises according to the smoothed probability is relatively smaller compared to the time dummies. In addition, the transition probabilities capture crises regimes that are not included in the time dummies, so the Markov switching model might provide other insights.

Table 5 provides the Markov regime switching regression estimates for the equation that includes control variables for common random shocks and Baker \& Wurgler's sentiment index. The upper panel provides the estimates during high volatility periods (crisis state), while the lower panel provides the estimates for low volatility periods (normal state). Similar to model (6) from, oil and gold returns do not drive dynamic conditional correlations in both states. Consistently, a statistically significant (at the 1\% level) negative effect of the Fed Fund Rate on 10 out of the 11 dynamic conditional correlations, in both states. In addition, investor sentiment seems to be negatively associated in both states. However, this association is stronger and consistent during the high volatility regime, since all coefficients are negative and statistically significant. The last row of table 9 reports the $\chi^{2}$ Wald test statistic for investor sentiment equality across both states. All Wald test statistics indicate that the investor sentiment coefficient differs statistically significant (at the $5 \%$ ) across the regimes for each country in the sample. This supports the second hypothesis that investor sentiment drives contagion during crisis periods. Lastly, the hypothesis that this effect differs for developed markets, compared to emerging markets, is rejected for the high volatility regime $(F=1.56)$. Therefore, there is not sufficient evidence to claim that contagion is stronger in emerging markets. Controlling for common random shocks, in a Markov regime switching model, does not alter the results presented in the previous section.

Table 6 provides the Markov regression estimates for investor sentiment, controlled for trade related variables. Consistent with equation 7 (table 4), inflation rates, growth in industrial production, import and export growth exhibit no significant explanatory power with respect to dynamic conditional correlations. This finding holds across both regimes. The U.S. Terms of Trade and exchange rate volatility have a negative and significant effect on dynamic correlation for most countries in both regimes. More importantly, in line with the previous results, is that the effect of 
investor sentiment in the volatile regime becomes significantly stronger than in the normal regime (as indicated by the Wald test in the last row). Furthermore, there is no evidence that contagion effects are stronger in emerging markets after controlling for trade related characteristics. Thus, table 6 presents results in favour of hypothesis 1 and 2 .

Table 7 presents the Markov switching regression estimates for investor sentiment, controlled for a set of financial characteristics. Similar to the other Markov switching regression estimates, there exists a large similarity between table 7 and its SUR variant in table 4 (model 8). The VIX is documented to be insignificant in explaining the dynamic conditional correlation across each country for both regimes. A similar inference can be made for Pastor's liquidity factor, the interaction between liquidity and investor sentiment, and the M2 money supply growth. Furthermore, sales and purchases of bonds and stocks to and by U.S. citizens have no significant impact on the left tail dependence. The Wald test statistics indicate that the effect of investor sentiment on the dynamic correlation differs significantly by regime. More specifically, this effect is documented to be larger in magnitude during crises periods. This effect, however, is not larger for emerging markets within the volatility regime $(F=0.63)$. Therefore, based on this robustness check, the results are not qualitatively different when crisis periods are endogenously determined. A sample selection bias seems not to be substantial enough to becloud the initial results.

\section{Conclusion and Discussion}

The occurrence of financial crises is an unavoidable and unfortunate byproduct of our modern economic system. A stylized fact is that financial crashes are often clustered. Several explanations have been put forward to explain this stylized fact, such as interdependence and contagion. The aim of this article is to investigate the presence of contagion effects in equity markets during 1990-2015. Specifically, this article contributes to the literature by exploring the role of investor sentiment as a determinant for financial contagion. It is found that equity markets become more dependent during crises periods. In addition, a strong negative relationship between investor sentiment and cross-equity market correlations is documented, which becomes even stronger during crises periods. This finding implies the existence of contagion effects in equity markets. This finding persists after the inclusion of a broad set of control variables and after allowing for endogenously determined crises periods.

During financial crises, when investor sentiment is low, domestic loss-averse investors will rebalance the share of risky assets in their portfolio and become more loss-averse. Such rebalancing may induce a declining price spiral in both the domestic as well as foreign market, creating a joint crash. In addition, during financial crises, investors tend to become more ambiguity averse. This causes them to feel less competent to assess the financial environment, resulting in herding behaviour. Herding behaviour, in turn, causes financial contagion. However, changes in correlations between equity markets is not solely driven by investor sentiment. Interdependence does also exhibit explanatory power: the Fed fund rate, the U.S. Terms of Trade, and exchange volatilities are negatively related to the time-varying correlations between equity markets.

Some limitations, however, of this paper needs to be addressed. First, the sample consisted of major developed equity markets, major emerging asset markets, and a time-span of 25 years, the results might not hold in other settings that were not explored here. Second, and more important, is the internal validity. One possible threat to the internal validity is an endogeneity issue embodied as an omitted variable bias. This article deploys a large set of control variables to limit omitted variable bias. In addition, the orthogonalized Baker \& Wurgler's sentiment index is used, which is uncorrelated with a large set of macro-fundamentals. Yet, the existence of unobserved heterogeneity correlated with the variables of interest can not be fully ruled out. In addition, there might exist an endogeneity problem in the form of a measurement error. No perfect proxies, without measurement error, for investor sentiment exist. To what extent endogeneity is problematic is unknown, but should be kept in mind.

Irrespective of the above-mentioned limitations, the presented results provide practical implications for financial regulators, and practitioners in the risk - and asset management industry. First, financial practitioners should become aware that international diversification of asset portfolios comes at an additional cost, namely contagion risk. During periods of low sentiment, contagion is likely to occur, which decreases diversification benefits due to co-crashes in different markets. The results of this article rationalizes the local equity preference of investors. Asset managers may exploit such preferences through the use of domestic mutual funds since such funds are expected to exhibit lower contagion risk. From the perspective of policy makers, this article suggests going beyond "classical" measures to mitigate contagion. Traditional expansionary monetary policy, via lower base interest rates, increases the dependency between markets substantially, increasing the risk for contagion. A question for policy makers is how to manage investor sentiment to avoid herding behaviour and panic selling in times of financial crises, since our global economic system is both too linked to fail and too contagious to ignore. 


\section{References}

Baker, M., \& Wurgler, J. (2006). Investor sentiment and the cross-section of stock returns. The Journal of Finance, 61(4), 1645-1680. https://doi.org/10.1111/j.1540-6261.2006.00885.x

Baker, M., Wurgler, J., \& Yuan, Y. (2012). Global, local, and contagious investor sentiment. Journal of Financial Economics, 104(2), 272-287. https://doi.org/10.1016/j.jfineco.2011.11.002

Barberis, N., Shleifer, A., \& Vishny, R. (1998). A model of investor sentiment. Journal of financial economics, 49(3), 307-343. https://doi.org/10.1016/S0304-405X(98)00027-0

Bikhchandani, S., Hirshleifer, D., \& Welch, I. (1992). A theory of fads, fashion, custom, and cultural change as informational cascades. Journal of Political Economy, 100(5), 992-1026. https://doi.org/10.1086/261849

Brown, J. R., Ivkovic, Z., Smith, P. A., \& Weisbenner, S. (2008). Neighbors matter: Causal community effects and stock market participation. The Journal of Finance, 63(3), 1509-1531. https://doi.org/10.1111/j.1540-6261.2008.01364.X

Brunnermeier, M. K., \& Pedersen, L. H. (2008). Market liquidity and funding liquidity. The review of Financial studies, 22(6), 2201-2238. https://doi.org/10.1093/rfs/hhn098

Calvo, Leiderman, \& Reinhart, C. M. (1996). Inflows of capital to developing countries in the 1990s. The Journal of Economic Perspectives, 10(2), 123-139. https://doi.org/10.1257/jep.10.2.123

Celik, S. (2012). The more contagion effect on emerging markets: The evidence of dcc-garch model. Economic Modelling, 29(5), 1946-1959. https://doi.org/10.1016/j.econmod.2012.06.011

Chiang, T. C., \& Zheng, D. (2010). An empirical analysis of herd behavior in global stock markets. Journal of Banking \& Finance, 34(8), 1911-1921. https://doi.org/10.1016/j.jbankfin.2009.12.014

Chiang, T. C., Jeon, B. N., \& Li, H. (2007). Dynamic correlation analysis of financial contagion: Evidence from Asian markets. Journal of International Money and Finance, 26(7), 1206-1228. https://doi.org/10.1016/j.jimonfin.2007.06.005

Christie, W. G., \& Huang, R. D. (1995). Following the pied piper: Do individual returns herd around the market? Financial Analysts Journal, 31-37. https://doi.org/10.2469/faj.v51.n4.1918

Corsetti, G., Pesenti, P., \& Roubini, N. (1999). Paper tigers? A model of the Asian crisis. European Economic Review, 43(7), 1211-1236. https://doi.org/10.1016/S0014-2921(99)00017-3

De Long, J. B., \& Shleifer, A. (1991). The stock market bubble of 1929: evidence from closed-end mutual funds. The Journal of Economic History, 51(3), 675-700. https://doi.org/10.1017/S0022050700039619

Devenow, A., \& Welch, I. (1996). Rational herding in financial economics. European Economic Review, 40(3), 603-615. https://doi.org/10.1016/0014-2921(95)00073-9

Dungey, M., \& Martin, V. L. (2001). Contagion across financial markets: An empirical assessment. Econometric Society.

Economou, F., Kostakis, A., \& Philippas, N. (2011). Cross-country effects in herding behaviour: Evidence from four south European markets. Journal of International Financial Markets, Institutions and Money, 21(3), 443-460. https://doi.org/10.1016/j.intfin.2011.01.005

Edison, H. J. (2003). Do indicators of financial crises work? An evaluation of an early warning system. International Journal of Finance \& Economics, 8(1), 11-53. https://doi.org/10.1002/ijfe.197

Engle, R. F., \& Sheppard, K. (2001). Theoretical and empirical properties of dynamic conditional correlation multivariate GARCH (No. w8554). National Bureau of Economic Research. https://doi.org/10.3386/w8554

Fong, W. M. (2003). Correlation jumps. Journal of Applied Finance, 13(1), 29.

Forbes, K. J., \& Rigobon, R. (2002). No contagion, only interdependence: measuring stock market comovements. The journal of Finance, 57(5), 2223-2261. https://doi.org/10.1111/0022-1082.00494

Frankel, J. A., \& Rose, A. K. (1996). Currency crashes in emerging markets: An empirical treatment. Journal of international Economics, 41(3), 351-366. https://doi.org/10.1016/S0022-1996(96)01441-9

Gerlach, S., \& Smets, F. (1995). Contagious speculative attacks. European Journal of Political Economy, 11(1), $45-63$. https://doi.org/10.1016/0176-2680(94)00055-O

Goldfajn, M. I., \& Valdes, M. R. O. (1997). Capital flows and the twin crises: the role of liquidity. International Monetary Fund. https://doi.org/10.5089/9781451850987.001 
Hartmann, P., Straetmans, S., \& De Vries, C. G. (2004). Asset market linkages in crisis periods. The Review of Economics and Statistics, 86(1), 313-326. https://doi.org/10.1162/003465304323023831

Heath, C., \& Tversky, A. (1991). Preference and belief: Ambiguity and competence in choice under uncertainty. Journal of risk and uncertainty, 4(1), 5-28. https://doi.org/10.1007/BF00057884

Hwang, S., \& Salmon, M. (2009). Sentiment and beta herding.

Kaminsky, G. L., \& Reinhart, C. M. (2000). On crises, contagion, and confusion. Journal of international Economics, 51(1), 145-168. https://doi.org/10.1016/S0022-1996(99)00040-9

King, M. A., \& Wadhwani, S. (1990). Transmission of volatility between stock markets. Review of Financial studies, 3(1), 5-33. https://doi.org/10.1093/rfs/3.1.5

Kodres, L. E., \& Pritsker, M. (2002). A rational expectations model of financial contagion. The journal of finance, 57(2), 769-799. https://doi.org/10.1111/1540-6261.00441

Kurov, A. (2010). Investor sentiment and the stock markets reaction to monetary policy. Journal of Banking \& Finance, 34(1), 139-149. https://doi.org/10.1016/j.jbankfin.2009.07.010

Lee, S. B., \& Kim, K. J. (1993). Does the October 1987 crash strengthen the co-movements among national stock markets? Review of Financial Economics, 3(1), 89.

Longin, F., \& Solnik, B. (1995). Is the correlation in international equity returns constant: 1960-1990? Journal of international money and finance, 14(1), 3-26. https://doi.org/10.1016/0261-5606(94)00001-H

Longin, F., \& Solnik, B. (2001). Extreme correlation of international equity markets. The journal of finance, 56(2), 649-676. https://doi.org/10.1111/0022-1082.00340

Masson, M. P. R. (1999). Multiple equilibria, contagion, and the emerging market crises (No. 99-164). https://doi.org/10.5089/9781451857979.001

Pastor, L., \& Stambaugh, R. F. (2003). Liquidity risk and expected stock returns. Journal of Political economy, 111(3), 642-685. https://doi.org/10.1086/374184

Rodriguez, J. C. (2007). Measuring financial contagion: A copula approach. Journal of Empirical Finance, 14(3), 401-423. https://doi.org/10.1016/j.jempfin.2006.07.002

Semlali, M. A. S., \& Collyns, M. C. (2002). Lending booms, real estate bubbles and the Asian crisis (No. 2-20). International Monetary Fund. https://doi.org/10.5089/9781451843859.001

Syllignakis, M. N., \& Kouretas, G. P. (2011). Dynamic correlation analysis of financial contagion: Evidence from the central and eastern European markets. International Review of Economics \& Finance, 20(4), 717-732. https://doi.org/10.1016/j.iref.2011.01.006

Thaler, R. H., \& Johnson, E. J. (1990). Gambling with the house money and trying to break even: The effects of prior outcomes on risky choice. Management science, 36(6), 643-660. https://doi.org/10.1287/mnsc.36.6.643

Tse, Y. K., \& Tsui, A. K. C. (2002). A multivariate generalized autoregressive conditional heteroscedasticity model with time-varying correlations. Journal of Business \& Economic Statistics, 20(3), 351-362. https://doi.org/10.1198/073500102288618496 


\section{Appendix}

Table 2. Seemingly unrelated regression on time-varying correlation for each country with the U.S.

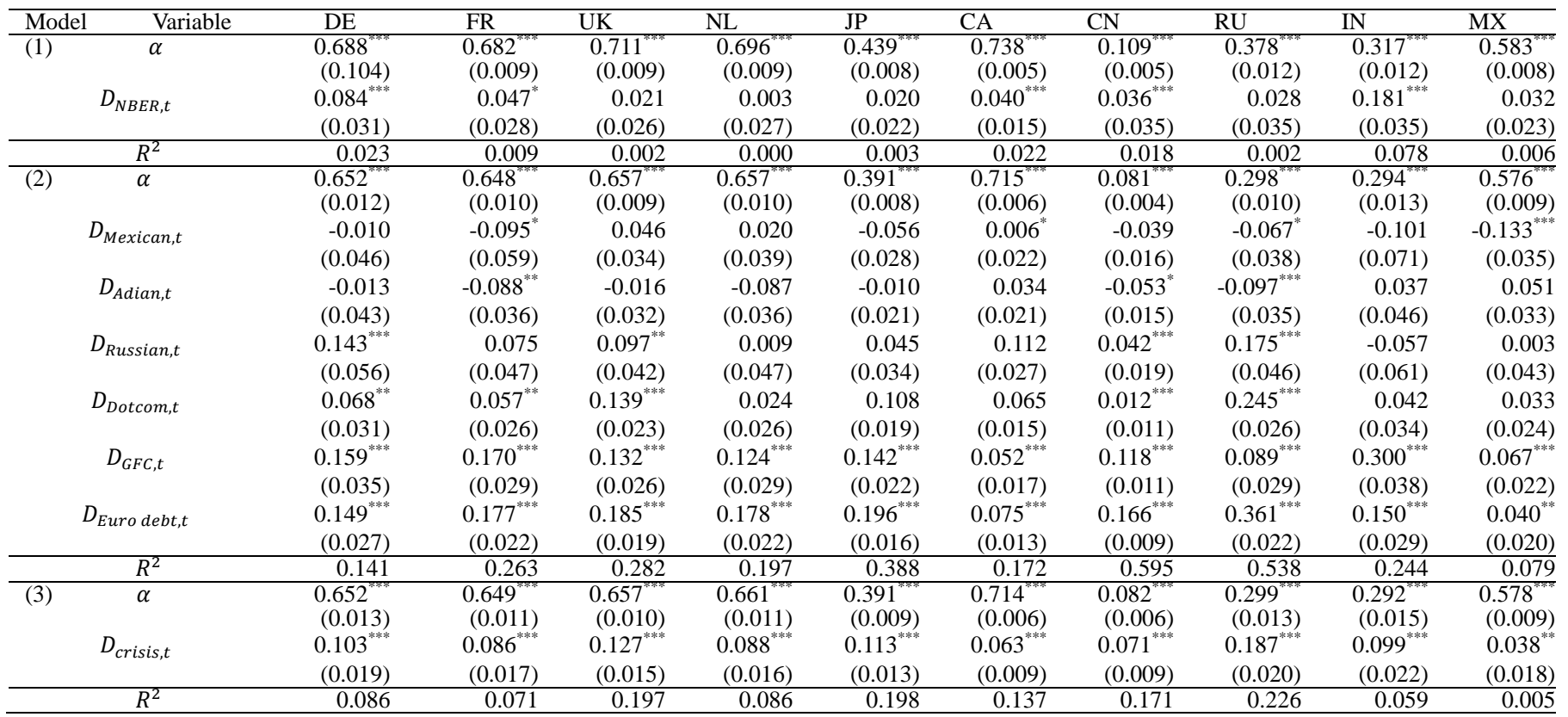

Model (1) only considers NBER recession dates. Model (2) considers six crises using six time dummies. Model (3) uses an aggregated time dummy which equals 1 if one of the 6 crises occurs in month t. $*, * *$, and $* * *$ indicate significance at the $10 \%, 5 \%$, and $1 \%$ levels, respectively. Robust standard errors are shown between parentheses

Table 3. Seemingly unrelated regression on time-varying correlation for each country with the U.S.

\begin{tabular}{|c|c|c|c|c|c|c|c|c|c|c|}
\hline Variable & DE & FR & UK & NL & JP & CA & $\mathrm{CN}$ & RU & IN & MX \\
\hline (4) & $\begin{array}{r}0.278 \\
(0088)\end{array}$ & $\begin{array}{c}0.267 \\
(0.080)\end{array}$ & $\begin{array}{r}0.480 \\
(0.077)\end{array}$ & $\begin{array}{c}0.372 \\
(0.077)\end{array}$ & $\begin{array}{c}0.160^{*} \\
(0.070)\end{array}$ & $\begin{array}{c}0.696 \\
(0.044)\end{array}$ & $\begin{array}{r}-0.019 \\
(0.045)\end{array}$ & $\begin{array}{r}0.108 \\
(0.112)\end{array}$ & $\begin{array}{l}-0.220^{*} \\
(0.106)\end{array}$ & $\begin{array}{c}0.531 \\
(0.076)\end{array}$ \\
\hline \multirow[t]{2}{*}{$D_{N B E R, t}$} & 0.521 & 0.351 & 0.111 & 0.275 & 0.104 & 0.158 & 0.095 & 0.057 & 0.62 & -0.241 \\
\hline & (00345) & $(0.314)$ & $(0.301)$ & $(0.301)$ & $(0.274)$ & $(0.172)$ & $(0.178)$ & $(0.443)$ & $(0.417)$ & $(0.297)$ \\
\hline \multirow[t]{2}{*}{$B E A R_{t}$} & $0.006^{* * *}$ & $0.007^{* * *}$ & $0.003^{* *}$ & $0.005^{* * *}$ & $0.005^{* * *}$ & 0.001 & $0.003^{* * *}$ & $0.004^{*}$ & $0.010^{* * *}$ & 0.002 \\
\hline & $(0.001)$ & $(0.001)$ & $(0.001)$ & $(0.001)$ & $(0.001)$ & $(0.001)$ & $(0.001)$ & $(0.002)$ & $(0.002)$ & $(0.001)$ \\
\hline \multirow[t]{2}{*}{$B U L L_{t}$} & $-0.006^{* * * *}$ & $-0.006^{* * * *}$ & $-0.004^{* * * *}$ & $-0.005^{* * *}$ & $-0.004^{* * * * *}$ & -0.001 & $-0.002^{*}$ & $-0.004^{*}$ & $-0.006^{* * *}$ & -0.000 \\
\hline & $(0.001)$ & $(0.001)$ & $(0.001)$ & $(0.001)$ & $(0.001)$ & $(0.001)$ & $(0.001)$ & $(0.002)$ & $(0.002)$ & $(0.001)$ \\
\hline \multirow[t]{2}{*}{$S E N T_{t}$} & $-0.128^{* * * *}$ & $-0.103^{* * *}$ & $-0.065^{* * *}$ & $-0.107^{* * *}$ & $-0.052^{* * *}$ & $-0.029^{* * * *}$ & $-0.062^{* * *}$ & $-0.057^{*}$ & $-0.073^{* * *}$ & -0.009 \\
\hline & $(0.017)$ & $(0.016)$ & $(0.015)$ & $(0.015)$ & $(0.014)$ & $(0.009)$ & $(0.009)$ & $(0.022)$ & $(0.021)$ & $(0.015)$ \\
\hline \multirow[t]{2}{*}{$B E A R_{t} * D_{N B E R, t}$} & -0.008 & -0.007 & -0.003 & -0.006 & -0.003 & -0.002 & -0.002 & -0.003 & -0.010 & 0.002 \\
\hline & $(0.005)$ & $(0.005)$ & $(0.004)$ & $(0.004)$ & $(0.004)$ & $(0.003)$ & $(0.003)$ & $(0.006)$ & $(0.006)$ & $(0.004)$ \\
\hline \multirow[t]{2}{*}{$B U L L_{t} * D_{N B E R, t}$} & -0.005 & -0.003 & -0.001 & -0.003 & -0.001 & -0.001 & -0.000 & 0.001 & -0.004 & 0.004 \\
\hline & $(0.004)$ & $(0.004)$ & $(0.004)$ & $(0.004)$ & (0.003) & $(0.002)$ & $(0.002)$ & $(0.006)$ & $(0.005)$ & $(0.004)$ \\
\hline \multirow{2}{*}{$S E N T_{t} * D_{N B E R, t}$} & $-0.116^{* * *}$ & $-0.091^{* * *}$ & $-0.089^{* * *}$ & $-0.086^{* * *}$ & $-0.066^{* * * *}$ & $-0.049^{* * *}$ & $-0.039^{* *}$ & $-0.100^{* *}$ & -0.013 & $-0.031^{* * *}$ \\
\hline & $(0.036)$ & $(0.033)$ & $(0.032)$ & $(0.032)$ & $(0.029)$ & $(0.018)$ & $(0.019)$ & $(0.046)$ & $(0.044)$ & $(0.007)$ \\
\hline \multirow[t]{2}{*}{$V I X_{t}$} & -0.070 & -0.066 & -0.018 & -0.025 & -0.018 & -0.023 & -0.016 & -0.066 & -0.082 & -0.048 \\
\hline & $(0.047)$ & $(0.043)$ & $(0.041)$ & $(0.041)$ & $(0.038)$ & $(0.024)$ & $(0.0$ & $(0.06$ & $(0.057)$ & (0.041) \\
\hline$R^{2}$ & 0.261 & 0.241 & 0.117 & 0.221 & 0.121 & 0.084 & 0.220 & 0.065 & 0.223 & 0.030 \\
\hline (5) & $0.325^{*}$ & 0.375 & $0.605^{* 3 *}$ & $0.428^{*}$ & 0.270 & $0.708^{*}$ & 0.0 & 0.227 & $-0.273^{*}$ & $0.550^{* * \pi}$ \\
\hline \multirow{2}{*}{$\begin{array}{r}\alpha \\
D_{\text {CRISIS }, t}\end{array}$} & (0.102) & $(0.096)$ & & $(0.092)$ & $(0.078)$ & & & & & $(0.095)$ \\
\hline & 0.290 & 0.113 & 0.089 & 0.246 & 0.075 & 0.085 & -0.005 & 0.226 & 0.223 & -0.063 \\
\hline & $(0.157)$ & $(0.147)$ & $(0.128)$ & $(0.141)$ & $(0.119)$ & $(0.078)$ & $(0.076)$ & $(0.188)$ & $(0.204)$ & $(0.146)$ \\
\hline \multirow[t]{2}{*}{$B E A R_{t}$} & $0.004^{*}$ & $0.003^{*}$ & -0.001 & 0.002 & 0.001 & -0.000 & 0.000 & -0.000 & $0.010^{* * *}$ & 0.001 \\
\hline & $(0.002)$ & $(0.002)$ & $(0.001)$ & $(0.001)$ & $(0.001)$ & (0.001) & $(0.001)$ & $(0.002)$ & $(0.002)$ & $(0.002)$ \\
\hline \multirow[t]{2}{*}{$B U L L_{t}$} & $-0.006^{* * *}$ & $-0.005^{* * *}$ & $-0.003^{*}$ & $-0.005^{* * *}$ & $-0.003^{* * *}$ & -0.001 & -0.001 & -0.002 & $-0.007^{* * *}$ & -0.000 \\
\hline & $(0.001)$ & $(0,00$ & & & & & & & & $(0.001)$ \\
\hline \multirow[t]{2}{*}{$S E N T_{t}$} & $-0.209^{* * * *}$ & $-0.132^{* * *}$ & $-0.118^{* * *}$ & $-0.122^{* * *}$ & $-0.078^{* * * *}$ & $-0.050^{* * *}$ & $-0.075^{* * *}$ & $-0.133^{* * *}$ & $-0.092^{* *}$ & -0.024 \\
\hline & $(0.026)$ & $(0.026)$ & & $(0.023)$ & $(0.020)$ & $(0.013)$ & & $(0.031)$ & $(0.033)$ & $(0.024)$ \\
\hline \multirow[t]{2}{*}{$B E A R_{t} * D_{\text {CRISIS }, t}$} & -0.000 & 0.003 & 0.003 & 0.000 & 0.003 & 0.000 & $0.003^{*}$ & 0.002 & -0.001 & 0.001 \\
\hline & $(0.002)$ & $(0.00$ & $(0.0$ & $(0.002)$ & $(0.002)$ & $(0.0$ & $(0.001)$ & $(0.003)$ & $(0.003)$ & $(0.002)$ \\
\hline \multirow[t]{2}{*}{$B U L L_{t} * D_{\text {CRISIS }, t}$} & $-0.005^{*}$ & -0.004 & -0.002 & $-0.005^{* * *}$ & -0.002 & -0.001 & -0.000 & -0.003 & -0.003 & 0.001 \\
\hline & $(0.002)$ & $(0.002)$ & $(0.002)$ & $(0.002)$ & $(0.002)$ & $(0.001)$ & $(0.001)$ & $(0.003)$ & $(0.003)$ & $(0.002)$ \\
\hline \multirow[t]{2}{*}{$S E N T_{t} * D_{\text {CRISIS }, t}$} & $-0.176^{* * * *}$ & $-0.093^{* * * *}$ & $-0.109^{* * *}$ & $-0.065^{* * *}$ & -0.061 & $-0.046^{* * *}$ & $-0.030^{*}$ & $-0.137^{* * *}$ & -0.055 & -0.024 \\
\hline & $(0.030)$ & $(0.028)$ & $(0.025)$ & $(0.027)$ & $(0.033)$ & $(0.015)$ & $(0.015)$ & $(0.036)$ & $(0.039)$ & $(0.028)$ \\
\hline \multirow[t]{2}{*}{$V I X_{t}$} & -0.077 & -0.071 & -0.015 & -0.023 & -0.014 & -0.026 & -0.018 & -0.057 & -0.104 & -0.049 \\
\hline & $(0.044)$ & $(0.041)$ & $(0.036)$ & $(0.039)$ & $(0.033)$ & $(0.022)$ & $(0.021)$ & $(0.053)$ & $(0.057)$ & $(0.041)$ \\
\hline$R^{2}$ & 0.3622 & 0.310 & 0.336 & 0.296 & 0.311 & 0.213 & 0.408 & 0.297 & 0.240 & 0.029 \\
\hline
\end{tabular}


Model (4) regresses the correlations on the proxies for investor sentiment and NBER time dummy. Model (5) replaces the NBER time dummy by the general crises dummy. $*, * *$, and $* * *$ indicate significance at the $10 \%, 5 \%$, and $1 \%$ levels, respectively. Robust standard errors are shown between parentheses.

Table 4. Seemingly unrelated regression on time-varying correlation for each country with the U.S

\begin{tabular}{|c|c|c|c|c|c|c|c|c|c|c|}
\hline Variable & DE & FR & UK & NL & JP & CA & $\mathrm{CN}$ & RU & IN & MX \\
\hline \multirow[t]{4}{*}{ (6) } & $0.785^{* * *}$ & $0.810^{* * *}$ & $0.800^{* * *}$ & $0.806^{* * *}$ & $0.523^{* * *}$ & $0.754^{* * *}$ & $0.166^{* * *}$ & $0.488^{* * *}$ & $0.412^{* * *}$ & $0.605^{* * *}$ \\
\hline & $(0.015)$ & $(0.012)$ & (0.009) & $(0.011)$ & $(0.008)$ & $(0.008)$ & $(0.006)$ & $(0.014)$ & $(0.021)$ & $(0.015)$ \\
\hline & $0.047^{* *}$ & $0.038^{* *}$ & $0.074^{* * * *}$ & $0.048^{* * * *}$ & $0.073^{* * * *}$ & $0.045^{* * *}$ & $0.055^{* * *}$ & $0.117^{* * * *}$ & $0.068^{* *}$ & 0.010 \\
\hline & $(0.016)$ & $(0.013)$ & $(0.010)$ & $(0.012)$ & $(0.009)$ & $(0.008)$ & $(0.006)$ & $(0.015)$ & $(0.022)$ & $(0.016)$ \\
\hline \multirow[t]{2}{*}{$F F R_{t}$} & $-2.797^{* * *}$ & $-4.120^{* * *}$ & $-3.736^{* * *}$ & $-3.790^{* * *}$ & $-3.614^{* * *}$ & $-0.876^{* * *}$ & $-2.213^{* * *}$ & $-5.146^{* * * *}$ & $-2.924^{* * *}$ & $-0.721^{* *}$ \\
\hline & $(0.334)$ & $(0.262)$ & $(0.211)$ & $(0.250)$ & (0.189) & (0.172) & (0127) & $(0.321)$ & $(0.464)$ & $(0.333)$ \\
\hline \multirow[t]{2}{*}{$R_{o i l, t}$} & 0.022 & 0.066 & $0.117^{* *}$ & 0.052 & 0.045 & 0.063 & 0.013 & 0.117 & -0.137 & -0.020 \\
\hline & $(0.075)$ & $(0.059)$ & $(0.047)$ & $(0.056)$ & $(0.043)$ & (0.039) & (0.029) & $(0.072)$ & (0.104) & $(0.075)$ \\
\hline \multirow[t]{2}{*}{$R_{\text {gold }, t}$} & $0.378^{*}$ & 0.252 & 0.086 & 0.166 & 0.106 & 0.093 & 0.058 & -0.055 & 0.224 & 0.093 \\
\hline & $(0.165)$ & $(0.130)$ & (0.104) & $(0.124)$ & (0.094) & $(0.085)$ & $(0.063)$ & (0.159) & $(0.230)$ & $(0.165)$ \\
\hline \multirow[t]{2}{*}{$S E N T_{t}$} & $-0.164^{* * *}$ & $-0.048^{* * *}$ & $-0.029^{* * *}$ & $-0.044^{* *}$ & 0.006 & $-0.029^{* * *}$ & $-0.020^{* * *}$ & -0.010 & -0.058 & -0.007 \\
\hline & $(0.025)$ & $(0.019)$ & $(0.015)$ & $(0.018)$ & (0.014) & $(0.013)$ & (0.009) & $(0.024)$ & (0.034) & $(0.024)$ \\
\hline \multirow[t]{2}{*}{$S E N T_{t} * D_{\text {crisis }, t}$} & $-0.161^{* * *}$ & $-0.054^{* * *}$ & $-0.072^{* * *}$ & $-0.036^{* *}$ & $-0.024^{* *}$ & $-0.037^{* *}$ & -0.000 & $-0.087^{* * *}$ & -0.037 & $-0.090^{* * *}$ \\
\hline & $(0.027)$ & $(0.021)$ & $(0.017)$ & $(0.018)$ & $(0.010)$ & $(0.014)$ & $(0.010)$ & $(0.026)$ & $(0.038)$ & $(0.027)$ \\
\hline$R^{2}$ & 0.448 & 0.577 & 0.655 & 0.573 & 0.667 & 0.272 & 0.684 & 0.609 & 0.243 & 0.028 \\
\hline \multirow[t]{2}{*}{ (7) } & $0.717^{* * *}$ & $0.127^{* * *}$ & $1.179^{* * * *}$ & $1.247^{* * *}$ & $1.546^{* * *}$ & $0.320^{* * * *}$ & $0.857^{* * * *}$ & $1.496^{* * * *}$ & $2.303^{* * *}$ & $\overline{0.351}$ \\
\hline & $(0.203)$ & $(0.124)$ & $(0.099)$ & $(0.114)$ & $(0.101)$ & $(0.091)$ & $(0.070)$ & $(0.226)$ & $(0.281)$ & $(0.206)$ \\
\hline \multirow[t]{2}{*}{$D_{\text {crisis }, t}$} & 0.026 & 0.007 & $0.040^{* * * *}$ & 0.014 & $0.038^{* * * *}$ & $0.021^{*}$ & $0.029^{* * * *}$ & $0.083^{* * *}$ & 0.036 & 0.030 \\
\hline & $(0.015)$ & $(0.010)$ & $(0.008)$ & $(0.009)$ & (0.009) & $(0.008)$ & $(0.006)$ & (0.019) & $(0.024)$ & $(0.018)$ \\
\hline \multirow[t]{2}{*}{$T O T_{U S, t}$} & 0.001 & $-0.005^{* * *}$ & $-0.005^{* * *}$ & $-0.005^{* * *}$ & $-0.012^{* * *}$ & $0.004^{* * * *}$ & $-0.008^{* * * *}$ & $-0.012^{* * *}$ & $-0.021^{* * *}$ & 0.003 \\
\hline & $(0.002)$ & $(0.001)$ & $(0.001)$ & $(0.001)$ & $(0.001)$ & $(0.001)$ & $(0.001)$ & $(0.002)$ & $(0.003)$ & $(0.002)$ \\
\hline \multirow[t]{2}{*}{$\pi_{U S, t}$} & 0.004 & -0.014 & -0.000 & -0.020 & -0.018 & 0.001 & -0.012 & -0.035 & -0.068 & -0.019 \\
\hline & $(0.025)$ & $(0.017)$ & $(0.013)$ & (0.014) & $(0.014)$ & $(0.014)$ & (0.009) & $(0.031)$ & (0.039) & $(0.027)$ \\
\hline \multirow[t]{2}{*}{$\pi_{j, t}$} & 0.003 & 0.017 & -0.005 & 0.000 & -0.006 & -0.009 & -0.004 & -0.002 & -0.021 & $-0.046^{* * *}$ \\
\hline & $(0.014)$ & $(0.019)$ & $(0.006)$ & $(0.006)$ & $(0.006)$ & $(0.008)$ & $(0.002)$ & $(0.004)$ & $(0.016)$ & $(0.008)$ \\
\hline \multirow[t]{2}{*}{$\Delta I P_{U S, t}$} & 0.005 & -0.003 & -0.007 & 0.005 & -0.006 & 0.000 & 0.000 & -0.004 & -0.036 & -0.002 \\
\hline & $(0.011)$ & $(0.007)$ & $(0.006)$ & $(0.006)$ & $(0.006)$ & $(0.006)$ & $(0.004)$ & $(0.014)$ & $(0.017)$ & $(0.012)$ \\
\hline \multirow[t]{2}{*}{$\Delta I P_{j, t}$} & -0.005 & 0.001 & -0.000 & -0.000 & 0.001 & -0.001 & -0.000 & -0.000 & 0.001 & 0.001 \\
\hline & $(0.003)$ & $(0.002)$ & $(0.003)$ & $(0.001)$ & $(0.001)$ & $(0.003)$ & & $(0.001)$ & $(0.002)$ & $(0.006)$ \\
\hline \multirow[t]{2}{*}{$\sigma_{e x}^{2}$} & $-0.237^{* * *}$ & $-0.007^{* * *}$ & 0.765 & $-0.105^{* * *}$ & -0.000 & $-0.725^{* * *}$ & $-0.027^{* * * *}$ & $-0.000^{* * * *}$ & $-0.000^{*}$ & -0.001 \\
\hline & $(0.029)$ & $(0.000)$ & $(0.627)$ & (0.009) & $(0.000)$ & (0.104) & $(0.002)$ & $(0.000)$ & $(0.000)$ & $(0.001)$ \\
\hline \multirow[t]{2}{*}{$\Delta \operatorname{Import}_{U S, j, t}$} & 0.001 & 0.000 & -0.000 & 0.000 & -0.000 & 0.000 & -0.000 & -0.000 & 0.000 & 0.002 \\
\hline & $(0.001)$ & $(0.000)$ & $(0.000)$ & $(0.000)$ & $(0.000)$ & $(0.000)$ & $(0.000)$ & $(0.000)$ & $(0.000)$ & $(0.002)$ \\
\hline \multirow[t]{2}{*}{$\Delta$ Export $_{U S, j, t}$} & -0.000 & -0.000 & 0.000 & -0.000 & 0.000 & -0.000 & -0.000 & 0.000 & -0.001 & -0.002 \\
\hline & $(0.001)$ & & $(0.000)$ & $(0.000)$ & $(0.000)$ & $(0.000)$ & $(0.000)$ & $(0.000)$ & $(0.001)$ & $(0.002)$ \\
\hline \multirow[t]{2}{*}{$S E N T_{t}$} & $-0.165^{* * *}$ & $-0.100^{* * *}$ & $-0.186^{* * *}$ & $-0.118^{* * *}$ & $-0.128^{* * * *}$ & $-0.053^{* * *}$ & $-0.073^{* * *}$ & $-0.173^{* * *}$ & $-0.120^{* * *}$ & -0.001 \\
\hline & $(0.025)$ & $(0.015)$ & $(0.011)$ & $(0.014)$ & $(0.012)$ & $(0.011)$ & $(0.026)$ & $(0.026)$ & $(0.033)$ & $(0.024)$ \\
\hline \multirow[t]{2}{*}{$S E N T_{t} * D_{\text {crisis }, t}$} & $-0.132^{* * *}$ & $-0.050^{* *}$ & $-0.177^{* * *}$ & $-0.065^{* * *}$ & $-0.119^{* * *}$ & $-0.037^{* *}$ & $-0.193^{* * *}$ & $-0.193^{* * *}$ & $0.086^{* *}$ & $-0.081^{* *}$ \\
\hline & $(0.028)$ & $(0.017)$ & $(0.013)$ & $(0.016)$ & $(0.014)$ & $(0.013)$ & $(0.031)$ & $(0.031)$ & $(0.039)$ & $(0.029)$ \\
\hline$R^{2}$ & 0.571 & 0.718 & 0.639 & 0.721 & 0.597 & 0.350 & 0.774 & 0.425 & 0.316 & 0.132 \\
\hline
\end{tabular}

Model (6) controls for common random shocks. Model (7) controls for trade linkages. *, **, and *** indicate significance at the $10 \%, 5 \%$, and $1 \%$ levels, respectively. Robust standard errors are shown between parentheses. 
Table 4 (continued). Seemingly unrelated regression on time-varying correlation for each country with the U.S.

\begin{tabular}{|c|c|c|c|c|c|c|c|c|c|c|}
\hline Variable & $\mathrm{DE}$ & FR & UK & NL & JP & CA & $\mathrm{CN}$ & $\mathrm{RU}$ & IN & MX \\
\hline \multirow[t]{3}{*}{ (8) } & $\begin{array}{c}0.744^{* * *} \\
(0.021)\end{array}$ & $\begin{array}{r}0.717^{* * *} \\
(0.012)\end{array}$ & $\begin{array}{c}0.745^{* * *} \\
(0.011)\end{array}$ & $\begin{array}{c}0.755^{* * *} \\
(0.011)\end{array}$ & $\begin{array}{c}0.417^{* * *} \\
(0.012)\end{array}$ & $\begin{array}{c}0.781^{* * *} \\
(0.008)\end{array}$ & $\begin{array}{c}0.099^{* * *} \\
(0.006)\end{array}$ & $\begin{array}{c}0.409^{* * * *} \\
(0.022)\end{array}$ & $\begin{array}{c}0.333^{* * *} \\
(0.024)\end{array}$ & $\begin{array}{c}0.627^{* * * *} \\
(0.020)\end{array}$ \\
\hline & $0.033^{* * * *}$ & 0.017 & $0.062^{* * * *}$ & 0.013 & $0.039^{* * * *}$ & $0.044^{* * * *}$ & $0.051^{* * *}$ & $0.140^{* * * *}$ & $0.076^{* *}$ & 0.019 \\
\hline & $(0.013)$ & $(0.011)$ & $(0.009)$ & $(0.010)$ & $(0.007)$ & $(0.008)$ & $(0.006)$ & $(0.021)$ & $(0.025)$ & $(0.018)$ \\
\hline \multirow{2}{*}{$V I X_{t}$} & -0.055 & -0.040 & -0.021 & -0.019 & -0.012 & $-0.033^{*}$ & -0.021 & -0.068 & -0.061 & -0.067 \\
\hline & $(0.036)$ & $(0.025)$ & $(0.020)$ & $(0.023)$ & $(0.016)$ & $(0.017)$ & $(0.015)$ & $(0.0$ & $(0.056)$ & (0.038) \\
\hline \multirow[t]{2}{*}{$L I Q_{-} t$} & -0.306 & -0.152 & -0.194 & -0.167 & 0.130 & 0.027 & 0.092 & 0.086 & -0.049 & -0.079 \\
\hline & $(0.205)$ & $(0.145)$ & (0.113) & (0.134) & (0.092) & (0.097) & $(0.084)$ & $(0.271)$ & $(0.321)$ & $(0.218)$ \\
\hline \multirow[t]{2}{*}{$L I Q_{t} * D_{\text {crisis }, t}$} & 0.411 & 0.276 & -.298 & 0.324 & 0.012 & 0.044 & 0.059 & 0.437 & -0.109 & -0.055 \\
\hline & $(0.239)$ & $(0.169)$ & $(0.131)$ & $(0.157)$ & $(0.107)$ & $(0.113)$ & $(0.097)$ & $(0.316)$ & $(0.371)$ & $(0.253)$ \\
\hline \multirow[t]{2}{*}{$\Delta M 2_{U S, t}$} & 0.023 & 0.015 & 0.012 & 0.021 & 0.004 & $0.025^{* *}$ & 0.010 & 0.044 & -0.004 & 0.007 \\
\hline & $(0.020)$ & $(0.014)$ & $(0.011)$ & $(0.013)$ & (0.009) & $(0.009)$ & $(0.008)$ & $(0.026)$ & $(0.031)$ & $(0.021)$ \\
\hline \multirow[t]{2}{*}{$\Delta M 2_{j, t}$} & 0.008 & -0.001 & 0.006 & -0.001 & 0.027 & $-0.029^{* * * *}$ & -0.000 & 0.003 & -0.003 & -0.010 \\
\hline & $(0.008)$ & $(0.002)$ & $(0.005)$ & (0.002) & (0.014) & $(0.009)$ & $(0.002)$ & $(0.002)$ & (0.003) & $(0.006)$ \\
\hline \multirow[t]{2}{*}{${\text { Bond } \text { Sale }_{t}}_{\text {}}$} & $-0.008^{* *}$ & $-0.003^{* *}$ & -0.092 & $0.004^{* * *}$ & 0.015 & 0.133 & -0.153 & $0.024^{* * * *}$ & 0.003 & -1.219 \\
\hline & $(0.003)$ & $(0.001)$ & (0.097) & $(0.002)$ & (0.010) & $(0.416)$ & $(0.813)$ & $(0.003)$ & (0.038) & (4.106) \\
\hline \multirow[t]{2}{*}{ Stock Sale $_{t}$} & 0.008 & $0.006^{* * *}$ & -0.195 & 1.418 & -0.002 & 0.100 & $0.105^{* * * *}$ & $-0.133^{*}$ & $0.037^{* *}$ & -0.014 \\
\hline & (0.004) & $(0.002)$ & $(0.151)$ & (2.602) & $(0.286)$ & $(0.660)$ & $(0.038)$ & $(0.052)$ & $(0.012)$ & $(0.012)$ \\
\hline \multirow[t]{2}{*}{ Bond Purchase $_{t}$} & 0.004 & 0.003 & -0.069 & 0.004 & $0.002^{* * *}$ & $-0.048^{* * *}$ & 0.272 & 0.002 & 0.124 & 0.007 \\
\hline & (0.004) & $(0.002)$ & $(0.136)$ & & & $(0.017)$ & & (0.006) & $(0.318)$ & (0.007) \\
\hline \multirow[t]{2}{*}{ Stock Purchase $_{t}$} & -0.136 & 0.059 & 0.146 & $-0.004^{*}$ & $0.005^{* * * *}$ & -0.360 & $0.025^{* * * *}$ & $-0.370^{*}$ & -0.119 & 0.005 \\
\hline & $(0.829)$ & & $(0.09$ & (0.002) & & $(0.429)$ & & $(0.147)$ & $(0.073)$ & (0.013) \\
\hline \multirow[t]{2}{*}{$S E N T_{t}$} & $-0.233^{* * * *}$ & $0.173^{* * *}$ & $-0.180^{* * * *}$ & $-0.126^{* * *}$ & $-0.070^{* * * *}$ & $-0.049^{* * * *}$ & $-0.047^{* * *}$ & $-0.172^{* * * *}$ & $-0.077^{* *}$ & -0.010 \\
\hline & $(0.024)$ & $(0.016)$ & $(0.012)$ & $(0.015)$ & $(0.011)$ & $(0.011)$ & $(0.009)$ & $(0.030)$ & $(0.035)$ & $(0.025)$ \\
\hline \multirow[t]{2}{*}{$L I Q_{t} * S E N T_{t}$} & $0.359^{*}$ & 0.180 & 0.074 & 0.087 & 0.005 & $0.172^{*}$ & -0.078 & -0.188 & 0.419 & 0.143 \\
\hline & (0.149) & (0.104) & $(0.081)$ & $(0.096)$ & $(0.066)$ & $(0.069)$ & $(0.060)$ & $(0.195)$ & $(0.227)$ & $(0.155)$ \\
\hline \multirow[t]{2}{*}{$S E N T_{t} * D_{\text {crisis }, t}$} & $-0.185^{* * *}$ & $-0.125^{* * *}$ & $-0.160^{* * *}$ & $-0.06^{* * *} 1$ & $-0.041^{* * * *}$ & $-0.035^{* *}$ & $-0.040^{* * *}$ & $-0.140^{* * * *}$ & -0.040 & 0.003 \\
\hline & $(0.027)$ & $(0.018)$ & $(0.014)$ & $(0.017)$ & $(0.012)$ & $(0.013)$ & $(0.01)$ & $(0.035)$ & $(0.040)$ & $(0.028)$ \\
\hline$R^{2}$ & 0.316 & 0.495 & 0.542 & 0.429 & 0.514 & 0.211 & 0.629 & 0.304 & 0.219 & 0.045 \\
\hline
\end{tabular}

Model (8) controls for financial linkages. $*, * *$, and $* * *$ indicate significance at the $10 \%, 5 \%$, and $1 \%$ levels, respectively. Robust standard errors are shown between parentheses

Table 5. Two-state Markov regime switching model on time-varying correlation for each country with the U.S.

\begin{tabular}{|c|c|c|c|c|c|c|c|c|c|c|c|c|}
\hline Model & & Jariable & $\mathrm{DE}$ & FR & UK & NL & JP & CA & $\mathrm{CN}$ & RU & IN & MX \\
\hline \multirow{2}{*}{\multicolumn{2}{|c|}{ High $\sigma^{2}$}} & $\alpha$ & $0.689^{* * *}$ & $0.860^{* * *}$ & $0.754^{* * *}$ & $0.766^{* * *}$ & $0.512^{* * *}$ & $0.760^{* * *}$ & $0.243^{* * *}$ & $0.447^{* * *}$ & $0.343^{* * *}$ & $0.555^{* * *}$ \\
\hline & & & $(0.030)$ & $(.004)$ & $(.023)$ & $(0.016)$ & $(0.007)$ & $(0.006)$ & $(0.004)$ & $(0.010)$ & $(0.014)$ & $(0.048)$ \\
\hline \multirow{2}{*}{\multicolumn{3}{|c|}{$F F R_{t}$}} & $-3.868^{* * * *}$ & $-2.708^{* * *}$ & $-4.930^{* * * *}$ & $-5.110^{* * *}$ & $-4.929^{* * *}$ & $-2.771^{* * * *}$ & $-2.956^{* * * *}$ & $-4.546^{* * *}$ & $-2.997^{* * * *}$ & -0.720 \\
\hline & & & $(0.325)$ & (0.135) & (0.409) & (0.334) & $(0.170)$ & $(0.219)$ & $(0.090)$ & $(0.261)$ & $(0.379)$ & (1.211) \\
\hline \multirow{2}{*}{\multicolumn{3}{|c|}{$R_{o i l, t}$}} & 0.062 & -0.017 & 0.143 & 0.003 & 0.021 & $0.209^{* * * *}$ & 0.004 & 0.041 & -0.152 & 0.105 \\
\hline & & & $(0.135)$ & $(0.024)$ & (0.095) & $(0.090)$ & $(0.040)$ & $(0.047)$ & $(0.021)$ & $(0.060)$ & (0.089) & $(0.242)$ \\
\hline \multirow{2}{*}{\multicolumn{3}{|c|}{$R_{\text {gold }, t}$}} & 0.486 & 0.034 & -0.178 & -0.110 & -0.044 & 0.080 & 0.075 & -0.193 & -0.021 & $1.162^{*}$ \\
\hline & & & $(0.363)$ & $(0.049)$ & $(0.277)$ & $(0.233)$ & $(0.105)$ & $(0.092)$ & $(0.045)$ & $(0.141)$ & $(0.201)$ & $(0.0589)$ \\
\hline \multirow{2}{*}{\multicolumn{3}{|c|}{$S E N T_{t}$}} & $-0.112^{* * *}$ & $-0.020^{* * *}$ & $-0.055^{* *}$ & $-0.060^{* *}$ & $-0.045^{* * *}$ & $-0.063^{* * *}$ & $-0.014^{* * *}$ & $-0.042^{* *}$ & $-0.226^{* * *}$ & $-0.178^{* * *}$ \\
\hline & & & $(0.034)$ & $(0.004)$ & $(0.027)$ & $(0.027)$ & $(0.011)$ & $(0.014)$ & $(0.003)$ & $(0.017)$ & $(0.026)$ & $(0.088)$ \\
\hline \multirow{2}{*}{\multicolumn{2}{|c|}{ Low $\sigma^{2}$}} & $\alpha$ & $0.845^{* * *}$ & $0.725^{* * *}$ & $0.850^{* * * *}$ & $0.850^{* * * *}$ & $0.597^{* * *}$ & $0.827^{* * * *}$ & $0.152^{* * *}$ & $0.664^{* * *}$ & $0.583^{* * *}$ & $0.622^{* * *}$ \\
\hline & & & $(0.006)$ & $(0.016)$ & $(0.005)$ & $(0.005)$ & $(0.006)$ & $(0.008)$ & $(0.005)$ & $(0.011)$ & $(0.021)$ & $(0.011)$ \\
\hline \multirow{2}{*}{\multicolumn{3}{|c|}{$F F R_{t}$}} & $-1.476^{* * *}$ & $-3.869^{* * *}$ & $-2.887^{* * *}$ & $-2.936^{* * *}$ & $-3.406^{* * *}$ & $-1.452^{* * *}$ & $-3.752^{* * *}$ & $-4.248^{* * *}$ & $-2.34^{* * *} 1$ & -0.318 \\
\hline & & & $(0.194)$ & $(0.325)$ & $(0.150)$ & $(0.143)$ & $(0.144)$ & $(0.167)$ & $(0.199)$ & $(0.348)$ & $(0.671)$ & $(0.355)$ \\
\hline \multirow{2}{*}{\multicolumn{3}{|c|}{$R_{o i l, t}$}} & -0.020 & 0.011 & 0.019 & -0.024 & 0.015 & -0.014 & 0.016 & 0.094 & -0.142 & -0.033 \\
\hline & & & $(0.032)$ & (0.089) & $(0.030)$ & $(0.029)$ & $(0.031)$ & $(0.033)$ & (0.028) & $(0.074)$ & $(0.118)$ & $(0.076)$ \\
\hline \multirow{2}{*}{\multicolumn{3}{|c|}{$R_{\text {gold }, t}$}} & -0.001 & -0.104 & -0.016 & 0.080 & 0.064 & 0.026 & -0.046 & -0.219 & 0.153 & $-0.344^{* *}$ \\
\hline & & & $(0.068)$ & $(0.230)$ & $(0.061)$ & (0.059) & $(0.061)$ & $(0.078)$ & $(0.065)$ & $(0.156)$ & $(0.207)$ & $(0.145)$ \\
\hline \multirow{2}{*}{\multicolumn{3}{|c|}{$S E N T_{t}$}} & $-0.014^{* * *}$ & 0.004 & $-0.022^{* * *}$ & $-0.020^{* * *}$ & $0.020^{* * *}$ & 0.009 & 0.015 & $0.057^{* * *}$ & $-0.057^{* * *}$ & 0.008 \\
\hline & & & $(0.005)$ & $(0.025)$ & $(0.005)$ & $(0.005)$ & $(0.005)$ & $(0.005)$ & $(0.009)$ & $(0.010)$ & $(0.015)$ & $(0.011)$ \\
\hline \multicolumn{3}{|c|}{$\chi_{1}^{2}$} & 8.02 & 9.30 & 7.53 & 20.74 & 32.30 & 24.14 & 8.14 & 26.49 & 30.45 & 4.28 \\
\hline
\end{tabular}

Dynamic conditional correlations are regressed on investor sentiment and proxies for common random shocks. The upper panel provides the estimates in the high volatility regime. The lower panel shows the estimates in the low volatility regime. $\chi_{1}^{2}$ provides the Wad test statistic of the hypothesis that $\mathbf{S E N T}_{\mathbf{t}}$ differs by regime. *, **, and *** indicate significance at the $10 \%, 5 \%$, and $1 \%$ levels, respectively. 
Table 6. Two-state Markov regime switching model on time-varying correlation for each country with the U.S.

\begin{tabular}{|c|c|c|c|c|c|c|c|c|c|c|c|}
\hline Variable & $\mathrm{DE}$ & FR & UK & NL & JP & $\mathrm{CA}$ & $\mathrm{CN}$ & $\mathrm{RU}$ & & & $\mathrm{MX}$ \\
\hline \multirow[t]{2}{*}{ High $\sigma^{2}$} & 0.413 & 1.532 & 1.533 & 0.875 & 1.655 & 0.258 & 0.511 & & - & 2.808 & 0.575 \\
\hline & (0.123) & $(0.226)$ & $(0.075)$ & (0.118) & $(0.081)$ & $(0.062)$ & $(0.051)$ & & & $(0.354)$ & (0.159) \\
\hline \multirow[t]{2}{*}{$T_{O T T_{U S, t}}$} & -0.004 & -0.010 & -0.008 & -0.001 & -0.013 & -.0005 & -0.004 & & - & -0.028 & 0.001 \\
\hline & $(0.001)$ & $(0.002)$ & $(0.001)$ & $(0.001)$ & $(0.001)$ & $(0.001)$ & $(0.01)$ & & & (0.004) & $(0.002)$ \\
\hline \multirow{2}{*}{$\pi_{U S, t}$} & -0.020 & -0.001 & 0.013 & -0.041 & -0.005 & 0.007 & -0.019 & & - & -0.150 & -0.021 \\
\hline & $(0.017)$ & $(0.012)$ & $(0.011)$ & (0.016) & $(0.013)$ & (0011) & $(0.010)$ & & & (0.069) & (0.024) \\
\hline \multirow[t]{2}{*}{$\pi_{j, t}$} & -0.000 & -0.091 & 0.008 & 0.010 & -0.012 & -0.003 & -0.020 & & - & 0.014 & 0.004 \\
\hline & (0.014) & $(0.013)$ & $(0.008)$ & (0.009) & $(0.010)$ & $(0.008)$ & (0.004) & & & $(0.019)$ & (0.009) \\
\hline \multirow[t]{2}{*}{$\Delta I P_{U S, t}$} & -0.003 & -0.053 & 0.000 & 0.0007 & -0.027 & 0.003 & -0.001 & & - & -0.034 & -0.013 \\
\hline & (0.007) & (0.006) & (0.004) & (0.007) & $(0.005)$ & (0.004) & (0.004) & & & $(0.023)$ & $0.011)$ \\
\hline \multirow[t]{2}{*}{$\Delta I P_{j, t}$} & -0.004 & -0.014 & -0.009 & 0.000 & -0.001 & -0.000 & -0.000 & & - & 0.002 & -0.003 \\
\hline & $(0.003)$ & $(0.002)$ & $(0.003)$ & (0002) & $(0.001)$ & $(0.003)$ & $(0.001)$ & & & $(0.002)$ & (0.005) \\
\hline \multirow[t]{2}{*}{$\sigma_{e x}^{2}$} & -0.217 & -0.017 & -3.723 & -0.149 & 0.000 & 0855 & -0.048 & & - & -0000 & -0.001 \\
\hline & $(0.016)$ & $(0.000)$ & $(0.776)$ & (0.009) & $(0.000)$ & $(0.095)$ & (0.004) & & & $(0.000)$ & $(0.000)$ \\
\hline \multirow[t]{2}{*}{$\Delta$ Import $_{U S, j, t}$} & 0.000 & 0.001 & 0.000 & 0.000 & -0.000 & -0.001 & -0.000 & & - & 0.001 & 0.000 \\
\hline & $(0.000)$ & $(0.000)$ & $(0.000)$ & $(0.000)$ & $(0.000)$ & $(0.001)$ & $(0.000)$ & & & $(0.001)$ & $(0.001)$ \\
\hline \multirow[t]{2}{*}{$\Delta$ Export $_{U S, j, t}$} & -0.000 & 0.000 & -0.000 & -0.000 & 0.000 & 0.001 & 0.000 & & - & 0.000 & 0.000 \\
\hline & $(0.001)$ & $(0.000)$ & $(0.000)$ & $(0.000)$ & $(0.000)$ & $(0.001)$ & $(0.000)$ & & & $(0.001)$ & $(.001)$ \\
\hline \multirow[t]{2}{*}{$S E N T_{t}$} & -0.033 & -0.135 & -0.132 & -0.058 & -0.015 & -0.046 & -0.023 & & - & -0.166 & -0.009 \\
\hline & $(0.008)$ & $(0.025)$ & $(0.009)$ & $(0.007)$ & $(0.004)$ & $(0.007)$ & $(0.010)$ & & & $(0.043)$ & $(0.010)$ \\
\hline \multirow[t]{2}{*}{ Low $\sigma^{2}$} & 1.557 & 0.87 & 1.245 & 1.274 & 1968 & -0.060 & 0.594 & & - & 1.712 & 0.741 \\
\hline & (1.163) & $(0.117)$ & $(0.512)$ & $(0.0232)$ & $(0.135)$ & $(0.505)$ & $(0.052)$ & & & $(0.180)$ & $(0.176)$ \\
\hline \multirow[t]{2}{*}{$T O T_{U S, t}$} & -0.010 & -0.000 & -0.008 & -0.007 & -0.018 & -0.007 & -0.004 & & - & -0.013 & -0.006 \\
\hline & (0013) & $(0.001)$ & $(0.005)$ & $(0.003)$ & $(0.002)$ & $(0.005)$ & $(0.001)$ & & & $(0.002)$ & $(0.002)$ \\
\hline \multirow[t]{2}{*}{$\pi_{U S, t}$} & -0.087 & -0.023 & -0.047 & -0.119 & -0.006 & 0.018 & 0.001 & & - & -0.030 & 0.261 \\
\hline & $(0.079)$ & $(0.018)$ & $(0.064)$ & $(0.016)$ & $(0.023)$ & $(0.044)$ & $(0.008)$ & & & $(0.026)$ & $(0.030)$ \\
\hline \multirow[t]{2}{*}{$\pi_{j, t}$} & -0.006 & -0.024 & -0.064 & 0.200 & -0.008 & -0.0233 & -0.004 & & - & 0.004 & 0.003 \\
\hline & $(0.034)$ & $(0.029)$ & $(0.027)$ & $(0.021)$ & $(0.013)$ & $(0.028)$ & $(0.003)$ & & & $(0.011)$ & $(0.00)$ \\
\hline \multirow[t]{2}{*}{$\Delta I P_{U S, t}$} & -0.042 & 0.001 & 0.030 & -0.148 & 0.005 & 0.001 & -0.004 & & - & -0.037 & -0.080 \\
\hline & $(0.044)$ & $(0.007)$ & $(0.034)$ & $(0.011)$ & $(0.008)$ & (0019) & $(0.003)$ & & & $(0.012)$ & $(0.010)$ \\
\hline \multirow[t]{2}{*}{$\Delta I P_{j, t}$} & 0.001 & -0.000 & -0.001 & -0.013 & 0.003 & -0.005 & -0.000 & & - & -0.001 & 0.020 \\
\hline & $(0.011)$ & $(0.003)$ & $(0.018)$ & $(0.002)$ & $(0003)$ & $(0.010)$ & $(0.000)$ & & & $(0.001)$ & (0.004) \\
\hline \multirow[t]{2}{*}{$\sigma_{e x}^{2}$} & -0.296 & -0.009 & -13.722 & -0.290 & -0.000 & 1.793 & -0.053 & & - & -0.000 & -0.001 \\
\hline & $(0.091)$ & $(0.000)$ & $(0.533)$ & $(0.023)$ & $(0.000)$ & $(0.473)$ & $(0.002)$ & & & $(0.000)$ & $(0.000)$ \\
\hline \multirow[t]{2}{*}{$\Delta \operatorname{Import}_{U S, j, t}$} & 0.001 & 0.000 & 0.0002 & -0.000 & -0.001 & 0.000 & -0.000 & & - & -0.001 & -0.008 \\
\hline & $(0.002)$ & $(0.000)$ & $(0.001)$ & $(0.000)$ & $(0.001)$ & $(0.002)$ & $(0.000)$ & & & $(0.001)$ & $(0.002)$ \\
\hline \multirow[t]{2}{*}{$\Delta \operatorname{Export}_{U S, j, t}$} & 0.002 & 0.000 & -0.001 & -0.003 & 0.000 & -0.001 & -0.000 & & - & 0.000 & 0.005 \\
\hline & $(0.002)$ & $(0.000)$ & $(0.001)$ & $(0.000)$ & $(0.001)$ & $(0.002)$ & $(0.000)$ & & & $(0.000)$ & $(0.001)$ \\
\hline \multirow[t]{2}{*}{$S E N T_{t}$} & -0.029 & -0.058 & 0.144 & 0.007 & 0.065 & 0.060 & -0.012 & & - & -0.041 & 0.006 \\
\hline & $(0.043)$ & $(0.007)$ & $(0.019)$ & $(0.010)$ & $(0.022)$ & $(0.022)$ & $(0.002)$ & & & $(0.010)$ & $(0.023)$ \\
\hline$\chi_{1}^{2}$ & 10.31 & 8.93 & 175.46 & 12.67 & 13.23 & 23.14 & 6.83 & & - & 9.09 & 3.51 \\
\hline
\end{tabular}

Dynamic conditional correlations are regressed on investor sentiment and proxies for trade linkages. The upper panel provides the estimates in the high volatility regime. The lower panel shows the estimates in the low volatility regime. $\chi_{1}^{2}$ provides the Wad test statistic of the hypothesis that $\mathbf{S E N T}_{\mathbf{t}}$ differs by regime. Russia is excluded due to optimisation issues. $*, * *$, and $* * *$ indicate significance at the $10 \%, 5 \%$, and $1 \%$ levels, respectively. 
Table 7. Two-state Markov regime switching model on time-varying correlation for each country with the U.S.

\begin{tabular}{|c|c|c|c|c|c|c|c|c|c|c|}
\hline Variable & $\mathrm{DE}$ & FR & UK & NL & JP & $\mathrm{CA}$ & $\mathrm{CN}$ & $\mathrm{RU}$ & IN & MX \\
\hline \multirow[t]{2}{*}{ High $\sigma^{2}$} & 0.344 & 0.732 & 0.655 & 0.703 & 0.308 & 0.577 & 0.122 & 0.274 & 0.149 & 0.438 \\
\hline & $(0.012)$ & (0.008) & (0.006) & $(0.010)$ & $(0.005)$ & $(0.013)$ & $(0.015)$ & (0.009) & (0.006) & $(0.015)$ \\
\hline \multirow{2}{*}{$V I X_{t}$} & 0.049 & -0.047 & -0.032 & -0.034 & -0.007 & 0.021 & -0.017 & 0.041 & -0.054 & 0.007 \\
\hline & $(0.062)$ & $(0.018)$ & (0.016) & (0.018) & $(0.016)$ & $(0.037)$ & $(0.017)$ & (0.024) & $(0.047)$ & $(0.160)$ \\
\hline \multirow[t]{2}{*}{$L I Q_{-} t$} & -0.353 & -0.058 & -0.037 & -0.070 & 0.005 & 0.059 & 0.004 & 0.142 & -0.225 & 0.327 \\
\hline & $(0.469)$ & $(0.045)$ & (0.004) & (0.067) & $(0.053)$ & $(0.026)$ & $(0.043)$ & $(0.186)$ & (0.166) & $(0.406)$ \\
\hline \multirow[t]{2}{*}{$\Delta M 2_{U S, t}$} & -0.187 & -0.012 & 0.010 & 0.012 & 0.001 & 0.007 & 0.018 & -0.015 & 0.018 & 0.0117 \\
\hline & $(0.064)$ & $(0.007)$ & (0.004) & (0.009) & $(0.009)$ & $(0.024)$ & (0.008) & $(0.023)$ & $(0.026)$ & $(0.073)$ \\
\hline \multirow[t]{2}{*}{$\Delta M 2_{j, t}$} & -0.002 & -0.001 & 0.018 & -0.003 & 0.052 & -0.023 & 0.000 & -0.001 & -0.007 & 0.002 \\
\hline & $(0.012)$ & $(0.002)$ & (0.008) & $(0.002)$ & $(0.018)$ & $(0.022)$ & $(0.003)$ & $(0.001)$ & $(0.026)$ & $(0.016)$ \\
\hline \multirow[t]{2}{*}{ Bond Sale $_{t}$} & 0.011 & -0.003 & 0.000 & 0.002 & -0.001 & 0.001 & -0.002 & 0.098 & 0.029 & -0.003 \\
\hline & $(0.099)$ & $(0.001)$ & $(0.000)$ & $(0.002)$ & $(0.001)$ & $(0.002)$ & $(0.001)$ & $(0.035)$ & (0.005) & $(0.015)$ \\
\hline \multirow[t]{2}{*}{ Stock Sale $_{t}$} & 0.028 & 0.011 & 0.002 & 0.007 & 0.021 & 0.005 & 0.009 & -0.373 & 0.077 & 0.019 \\
\hline & $(0.025)$ & (0.006) & $(0.001)$ & (0.004) & $(0.006)$ & (0.003) & (0.006) & $(0.067)$ & $(0.111)$ & (0.038) \\
\hline \multirow[t]{2}{*}{ Bond Purchase $_{t}$} & 0.007 & 0.009 & 0.014 & -0.005 & 0.006 & 0.007 & -0.087 & 0.005 & -0.004 & 0.034 \\
\hline & $(0.012)$ & $(0.020)$ & $(0.007)$ & $(0.003)$ & $(0.001)$ & $(0.004)$ & $(0.445)$ & $(0.009)$ & $(0.005)$ & $(0.023)$ \\
\hline \multirow[t]{2}{*}{ Stock Purchase $_{t}$} & 0.023 & 0.183 & -0.665 & 0.023 & 0.015 & -1.875 & 0.051 & 0.337 & 0.378 & -0.042 \\
\hline & $(0.090)$ & $(0.161)$ & $(0.372)$ & $(0.016)$ & $(0.020)$ & $(1.781)$ & $(0.048)$ & $(0.117)$ & (0.193) & (0.047) \\
\hline \multirow[t]{2}{*}{$S E N T_{t}$} & -0.115 & -0.024 & -0.063 & -0.054 & -0.049 & -0.061 & -0.028 & -0.067 & -0.219 & -0.302 \\
\hline & $(0.048)$ & $(0.005)$ & (0.004) & (0.007) & $(0.008)$ & $(0.026)$ & $(0.005)$ & $(0.019)$ & $(0.035)$ & $(0.081)$ \\
\hline \multirow[t]{2}{*}{$L I Q_{t} * S E N T_{t}$} & 0.232 & 0.014 & 0.023 & -0.027 & 0.116 & -0.082 & 0.034 & -0.012 & 0.759 & -1.300 \\
\hline & $(0.544)$ & $(0.070)$ & $(0.050)$ & $(0.097)$ & $(0.114)$ & $(0.261)$ & & $(0.016)$ & $(0.468)$ & $(0.945)$ \\
\hline \multirow[t]{2}{*}{ Low $\sigma^{2}$} & 0.618 & 0.477 & 0.440 & 0.482 & 0.222 & 0.763 & 0.055 & 0.536 & 0.402 & 0.606 \\
\hline & $(0.012)$ & $(0.016)$ & $(0.025)$ & (0.019) & $(0.017)$ & $(0.007)$ & $(0.007)$ & $(0.007)$ & $(0.023)$ & $(0.017)$ \\
\hline \multirow[t]{2}{*}{$V I X_{t}$} & -0.094 & -0.040 & 0.014 & -0.027 & -0.002 & -0.043 & 0.000 & -0.079 & -0.037 & -0.528 \\
\hline & (0.028) & (0.039) & $(0.046)$ & $(0.051)$ & (0.029) & $(0.015)$ & (0.011) & (0.043) & $(0.051)$ & $(0.034)$ \\
\hline \multirow[t]{2}{*}{$L I Q_{t}$} & 0.032 & -0.152 & -0.313 & -0.131 & -0.054 & -0.087 & 0.004 & 0.067 & -0.102 & -0.032 \\
\hline & $(0.073)$ & $(0.206)$ & $(0.217)$ & (0.154) & $(0.101)$ & $(0.048)$ & $(0.036)$ & $(0.110)$ & $(0.143)$ & (0.109) \\
\hline \multirow[t]{2}{*}{$\Delta M 2_{U S, t}$} & 0.030 & -0.038 & -0.022 & 0.050 & -0.007 & 0.018 & -0.008 & 0.021 & 0.061 & 0.014 \\
\hline & $(0.013)$ & $(0.029)$ & $(0.039)$ & $(0.031)$ & $(0.015)$ & $(0.008)$ & $(0.009)$ & $(0.019)$ & $(0.028)$ & (0.019) \\
\hline \multirow[t]{2}{*}{$\Delta M 2_{j, t}$} & -0.000 & 0.001 & -0.014 & -0.001 & -0.106 & 0.005 & -0.000 & -0.004 & -0.006 & -0.002 \\
\hline & $(0.000)$ & $(0.004)$ & $(0.012)$ & $(0.007)$ & $(0.016)$ & $(0.009)$ & $(0.002)$ & $(0.002)$ & $(0.003)$ & $(0.005)$ \\
\hline \multirow[t]{2}{*}{ Bond Sale $_{t}$} & -0.013 & 0.003 & 0.002 & -0.030 & -0.007 & -0.002 & -0.001 & -0.079 & 0.036 & -0.055 \\
\hline & (0.003) & (0.003) & $(0.001)$ & & & & & & $(0.043)$ & $(0.040)$ \\
\hline \multirow[t]{2}{*}{ Stock Sale $_{t}$} & 0.021 & 0.023 & 0.001 & 0.010 & 0.043 & -0.001 & 0.082 & -0.284 & 0.074 & -0.004 \\
\hline & $(0.040)$ & & $(0.001)$ & $(0.012)$ & $(0.002)$ & $(0.001)$ & $(0.047)$ & & $(0.051)$ & $(0.012)$ \\
\hline \multirow[t]{2}{*}{ Bond Purchase $_{t}$} & 0.034 & 0.009 & 0.322 & 0.053 & 0.005 & 0.002 & 3.036 & -0.030 & 0.101 & -0.013 \\
\hline & $(0.006)$ & $(0.007)$ & $(0.653)$ & (0.029) & $(0.001)$ & $(0.002)$ & (0.369) & $(0.017)$ & $(0.362)$ & $(0.095)$ \\
\hline \multirow[t]{2}{*}{ Stock Purchase $_{t}$} & -0.002 & -0.092 & -0.026 & 0.098 & 0.009 & 0.002 & 0.019 & 0.569 & -0.150 & 0.024 \\
\hline & $(0.002)$ & $(0.059)$ & $(0.370)$ & $(0.067)$ & $(0.005)$ & $(0.001)$ & $(0.004)$ & $(0.285)$ & $(0.082)$ & $(0.016)$ \\
\hline \multirow[t]{2}{*}{$S E N T_{t}$} & -0.050 & 0.050 & 0.014 & 0.002 & 0.067 & 0.007 & -0.015 & 0.033 & -0.041 & 0.013 \\
\hline & (0.008) & (0.019) & $(0.031)$ & $(0.019)$ & (0.008) & (0.006) & $(0.006)$ & $(0.013)$ & (0.019) & $(0.011)$ \\
\hline$L I Q_{t} * S E N T_{t}$ & 0.059 & 0.235 & 0.689 & 0.217 & 0.045 & 0.076 & 0.133 & 0.006 & 0.274 & 0.026 \\
\hline & $(0.107)$ & $(0.237)$ & $(0.583)$ & $(0.207)$ & $(0.096)$ & $(0.068)$ & $(0.072)$ & $(0.137)$ & $(0.160)$ & $(0.128)$ \\
\hline$\chi_{1}^{2}$ & 17.61 & 14.19 & 25.12 & 7.22 & 96.63 & 4.69 & 3.36 & 18.29 & 30.43 & 14.78 \\
\hline
\end{tabular}

Dynamic conditional correlations are regressed on investor sentiment and proxies for financial linkages. The upper panel provides the estimates in the high volatility regime. The lower panel shows the estimates in the low volatility

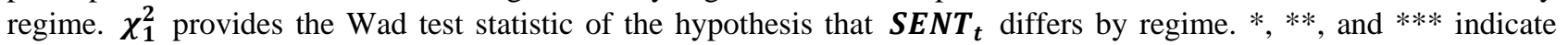
significance at the $10 \%, 5 \%$, and $1 \%$ levels, respectively.

\section{Copyrights}

Copyright for this article is retained by the author(s), with first publication rights granted to the journal.

This is an open-access article distributed under the terms and conditions of the Creative Commons Attribution license which permits unrestricted use, distribution, and reproduction in any medium, provided the original work is properly cited. 